UC-NRLF

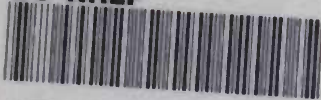

\$B $304 \quad 453$

\title{
SILOS
}

Construction Axd SERVICE M. L. KING

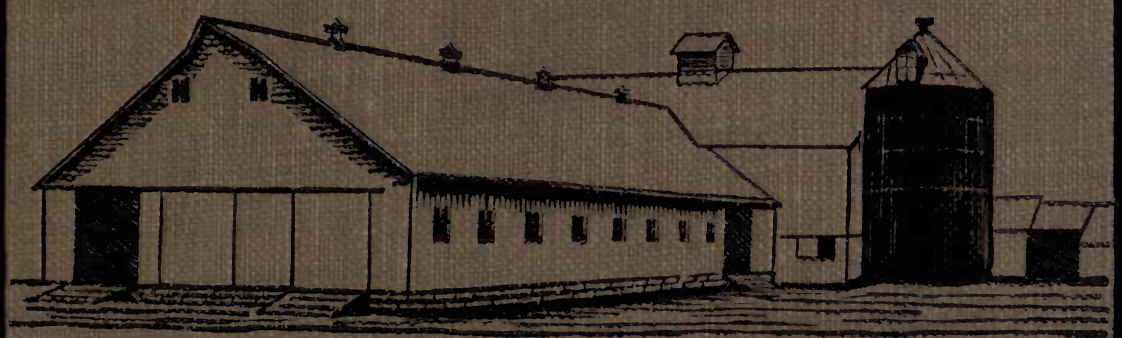




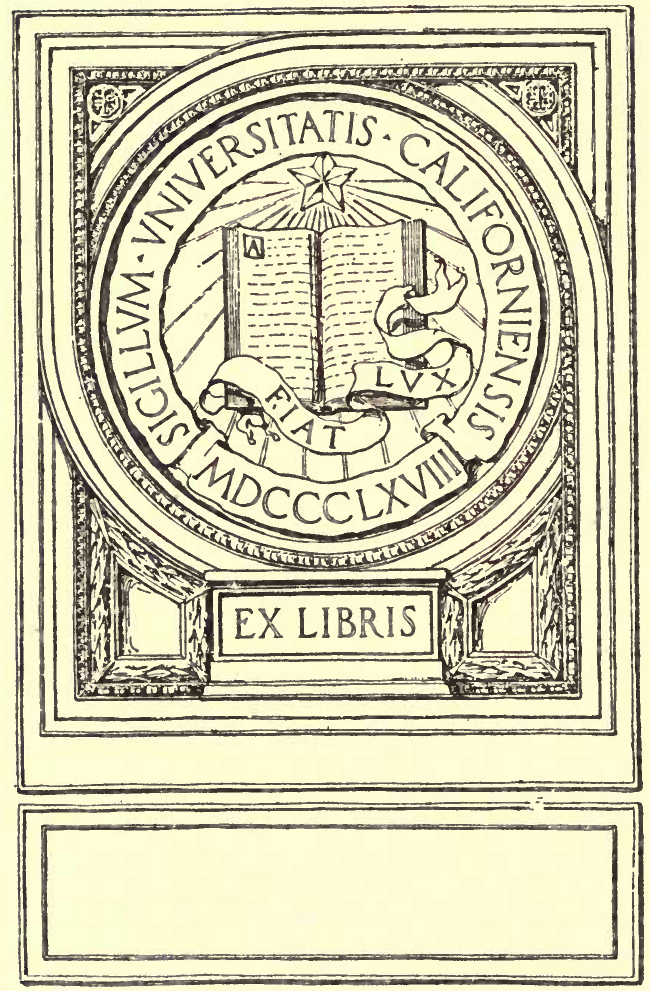






\title{
SILOS
}

\section{Construction and Service}

\author{
By \\ M. L. KING \\ Formerly Silo Investigation Expert, \\ Iowa State College
}
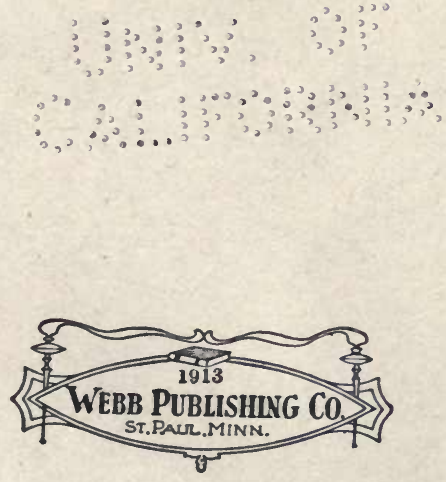


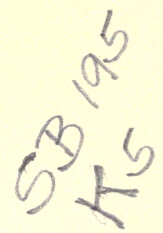

COPYRIGHT, 1913

$\mathrm{BY}$

WEBB PUBLISHING COMPANY

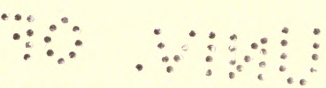

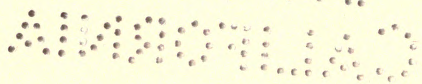




\section{PREFACE}

During the past few years, I have had occasion to examine and to study the construction of a large number of silos in a dozen states, both in the East and in the Middle West. As the result of this study I have become thoroughly impressed with the belief that many of the mistakes and difficulties in the building of silos might be avoided if the builders had a more thorough knowledge of the fundamental principles of silo construction and the preservation of silage. There is no recent American book on silo building and none of any date which covers the many types of silos now in use and gives details of their construction. There are a number of experiment station publications on the subject, but these are necessarily either brief in their treatment or limited to special types. It is with the object of presenting to the intending builder the principles of silo construction and the advantages and disadvantages of the different types, and more particularly of giving the actual methods of construction, that this book is written.

The first part of the volume takes up the fundamentals of silage preservation, descriptions of the different types of silos follow, and an explanation of the details and the construction of all the important types. These details and the $p$ ans and specifications are in nearly all cases from firsthand knowledge.

Where the information has occasionally been gleaned from others, full credit is given. The author wishes to acknowledge his indebtedness to all engineers and mechanics with whom he has associated in his silo work, as they have all contributed ideas very helpful in developing silos. Promi- 
nent among these should be mentioned C. H. VanZee, E. Y. Cable, and A. O. Alexander. For careful editing and helpful suggestions as to methods of presenting the facts contained in this volume, the author is very grateful to Professor Fred W. Beckman.

M. L. KING 


\section{CONTENTS}

Chapter

Page

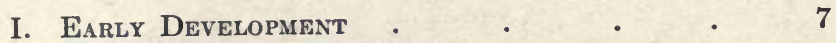

II. Fundamentals of Silage Preservation • 11

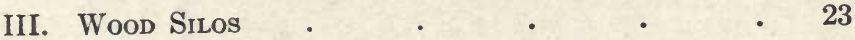

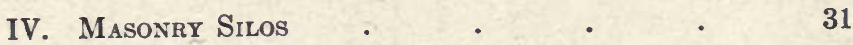

V. Planning the Silo $\quad$ - $\quad$ - $\quad$. 39

VI. Erection of Stave Silos a + • • 52

VII. Monolithic Concrete Silos . . 60

ViII. The Iowa System of Building Block Silos • 65

IX. Safe Strength of Materials • • • 84

X. Buying and Contracting Silos . $\quad 96$ 



\section{Silos: Construction and Service}

\section{CHAPTER I}

\section{EARLY DEVELOPMENT}

Origin. The silo probably originated in the southern part of Europe somewhat previous to 1845 .

Subsequent Development. The first silos used were simply pits in which green fodders were packed and covered with earth. Later these pits were made more permanent by lining with masonry. To keep the upper layer of this fodder moist and the whole more compact, the top was generally covered with earth or other heavy material. When the fodder was used it was found that the silage at the bottom was better preserved than that at the top, and that the amount of inferior silage at the top was practically the same, regardless of the depth of the silo. Thus the deeper pits had a smaller percentage of inferior silage than the shallow ones. The logical development, therefore, was to increase the depth of the silo pit. However, soil waters often limited the depth, so that it became necessary in many cases to build a superstructure, or what we now consider a silo.

Under modern conditions we find that in most cases it is cheaper to build above ground than below, so that today the silo generally goes into the ground only deep enough to secure a firm foundation; or in the case of a bank barn, it extends down to a level with the barn floor. For Northern or North Central states, the pit extends in the ground 3 or 4 feet, while the superstructure, or silo proper, in case of wood, is generally built 30 feet high. Wood silos should not be built much 
higher than this, unless extra precautions are taken in guying. With the masonry silo, the practical height is not less than 40 feet.

Development of the Round Silo. The original silos were built square or rectangular, but upon developing the high silos it was found that a large amount of silage spoiled in the corners. This lead to the boarding up of the corners with straight boards, making an octagonal silo; or bent lumber was used, making it round. This was a great improvement, but was only an intermediate step in the development of the

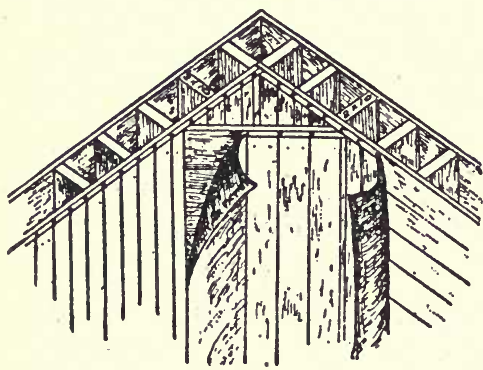

Fig. 1. Construction detals of the square silo. round silo, which, during the later part of the ' 80 's, became quite common.

Improvement of Door and Door-Frames. At first the round silo had only one door at the bottom, or none at all, all silage being lifted over the top It was gradually learned that doors could be maae as tight and smooth as the rest of the wall, and then silos became common with doors placed at more or less convenient intervals. In the square silos the doors were made continuous, just as in a grain bin. Likewise, in the early '90's, continuous doors became common in what is known as the Wisconsin or sheeted silo. It was only necessary to place rods across the doors to prevent the jambs from spreading. It was not quite such a simple matter to build continuous doors in the stave silos; therefore they were seldom used prior to 1896. Later a patent was issued covering this feature, and the use of continuous doors in stave silos has been more or less involved in litigation. 


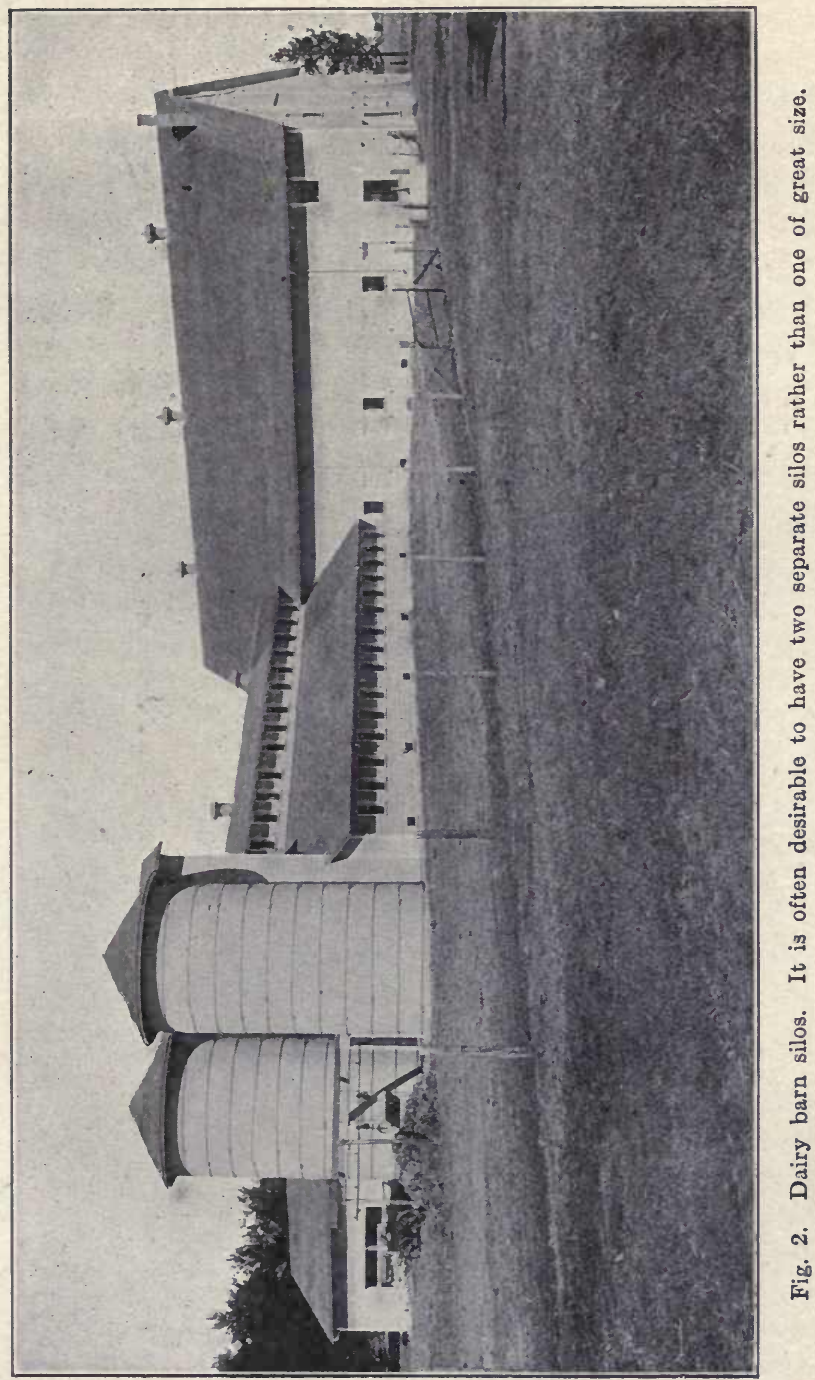


Development of the Masonry Silo. The use of wood and masonry in silo construction commenced at about the same time in the United States, namely, in the '70's. However, steel is necessary in the construction of masonry silos, and the lack of this general knowledge, together with the cost of steel, caused many serious failures. For this reason rapid advancement in the development of masonry silos has occurred only since the beginning of the present century. Masonry silos were originally built with very thick walls, 2 feet or even more being a common thickness. By the use of a combination of steel and masonry, 3 to 6 inches is sufficient. The establishment of this fact has, of course, been a great factor in the development of an economical masonry silo.

The general features of the modern silo are greater height, smaller diameter, and convenience in construction and use. 


\section{CHAPTER II}

\section{FUNDAMENTALS OF SILAGE PRESERVATION}

Nature of the Process. In the silo the corn or other fodder undergoes a slight chemical change quite similar to that which occurs in making sauerkraut. The latter is such a well known process and is so similar to the preservation of silage that the comparison is oftentimes used. In the formation of silage, the action of two principal kinds of bacteria determines its quality. These are the bacteria that form lactic acid and those that form acetic acid.

In the early development of the silo, it was common to cut the corn quite green, which condition favors the formation of acetic acid. Acetic acid is very much stronger than lactic acid, and silage containing much of it is what is ordinarily considered sour silage.

Time for Cutting. The present practice is to permit the corn to become as ripe as possible without losing much moisture. That is, the corn should become well dented and glazed, but should not be given opportunity to harden or dry out. When a few leaves near the bottom of the stalk have dried and the same with the husks, that indicates about the proper time for filling the silo. The silage made from such corn will be what is known as sweet silage. The acid formed will be principally lactic. Within a very few hours after the corn is placed in the silo it begins to heat. Only a certain percentage of acid can form, as it kills the bacteria and thus automatically controls acidity. The rise of temperature also aids in the destruction of the bacteria.

Quality of the Silage at the Wall. At the wall of any silo the rise in temperature due to fermentation is interfered 
with on account of heat passing out through the wall; and since heat is one of the factors in checking fermentation, there are different conditions and results at the wall than in the center. This is noticeable in any kind of silo. In silage taken from against the wall, a slight difference in odor can always be detected, no matter how good and tight the walls are. This does not mean that the silage at the wall is materially inferior to that elsewhere, nor does it mean that just because there is a little difference in the odor the silage is all bad. The writer has never found a silo in which this difference could not be detected.

With a rise in temperature, any material is certain to expand. The silage settles very rapidly the first few days, and this, together with the rise of temperature, is the main source of the outward pressure; during the first few days after the silo is filled it is greater than at any other time.

The growth of mold or the decay of the silage can only occur when air is admitted. If the silage is at all dry and air is admitted mold results. If, however, the moisture content runs as high as 65 to 70 per cent, and air enters, the result is usually rotten silage. It is important to mention this, as the rotten silage prevents air from reaching the rest of the silage, so the loss in this case is usually not very great. In the ease of dry silage, however, the admission of air causes a growth of mold which does not prevent to so great an extent the entrance of air.

The growth of mold does not effectively prevent air from reaching adjoining silage. Therefore the loss is often much more serious than would have been the case with more moisture in the silage. In some cases concrete silos could more appropriately be called gravel silos, as they allow the air to filter through and at the same time absorb moisture from the silage, making the conditions right for the development of 
heavy mold near the wall. This is not true of a good concrete silo, but has usually been the case where sufficient cement was not used.

Forage or Mold Poisoning. Some of these silage molds are poisonous, especially to horses. The following is a statement taken from Press Bulletin No. 30 (Iowa), by C. H. Stange, head of the Veterinary Department of the Iowa State College, with reference to this problem:

"Iowa farmers have suffered heavy losses in the past few months by the death of horses from a disease that affects these animals almost exclusively. It is usually fatal; it is not contagious, and it is quite certain that it comes from the eating of moldy fodder or grain. There is only one safeguard against it and that is the rejection of any feed that shows signs of mold. Ensilage and corn fodder of any kind and hay from swampy lands need to be inspected with special care, for they are the most likely to be moldy. Cattle often seem to eat spoiled plant food without harm, but to horses it is poisonous.

"This disease has been called by various names: Forage poisoning, cryptogamic poisoning, enzootic cerebritis, epizootic cerebro-spinal meningitis, leuco-encephalitis, etc.

"It usually appears in isolated outbreaks and generally the horses on a single farm in a community are affected. In some cases where horses are not fed alike, only those given a certain kind of feed are taken sick. In these facts there is quite conclusive evidence that the disease is associated with the food eaten and that it is not transmitted from one animal to another. The outbreaks appear more frequently in low, swampy districts because conditions there are more favorable for the development of the molds and the undesirable changes in plant foods believed to be responsible for the disease. It is not by any means confined to these districts, however, 
nor is it limited to any certain food stuff. It merely occurs more frequently in some foods than others, due to their nature and method of storing.

"Causes. Forage poisoning is likely to appear whenever moldy grain or fodder is fed to horses or mules, but it does not follow in every case where such food is given. Moreover, it very seldom affects cattle. Horses and mules may sometimes be fed for a considerable time on fodder containing more or less mold without sickness while in other cases a comparatively small amount of such feed will cause death in a short time. Danger lies in the use of fermented foods, also, on account of poisons developed in fermentation. Some plants are likewise poisonous at a certain stage of their growth or when partially wilted. This is true of sorghum, particularly the second growth, which in some cases causes almost instantaneous death.

"There are several molds which grow on food materials under certain conditions which are more or less injurious. The most common are the black mold, the blue mold and the green mold. They are found most frequently in ensilage, corn, hay, oats and ground feeds. Moisture favors their development on all food stuffs.

"Ensilage. Ensilage is one of the most important and valuable foods available to the Iowa farmer, but it is often responsible for forage poisoning. Sweet ensilage is of proved worth as a feed for horses as well as for cattle, but speaking generally ensilage feeding is attended by some dangers that the owners of silos should know. Ensilage contains the necessary moisture and, in most cases, the required heat, to favor the development of molds. On this account it is more often a cause of forage poisoning than other food stuffs. Perhaps 80 to 90 per cent of the outbreaks reported to this station come from feeding moldy ensilage. The quantity of mold 
may be so small as to be overlooked and yet be dangerous. Especially is that true of hay coming from low, marshy ground; though the mold in it may not be seen at first glance, there may be enough of it to produce poisoning and death.

"Moldy corn has been responsible for several outbreaks of forage poisoning. Ears that have been attacked by the corn ear worm are particularly liable to be moldy.

"Symptoms. Two forms of the disease are most common, the acute and sub-acute.

"In acute forage poisoning loss of appetite and lack of thirst, associated with depression and lack of spirit are usually the first symptoms. Following this usually come unsteadiness of gait and inability to control the hind quarters, which become worse until the animal either lies down or falls and is unable to rise. At the same time there is in practically all cases a paralysis of the muscles of the throat and cheeks as a result of which there is slobbering, due to inability to swallow, and a flabby condition of the cheeks, which appear swollen and pouched. After the animal is unable to rise it will sometimes lie quietly for hours, and sometimes it will struggle or show spasms at frequent intervals. In acute cases there is usually profuse sweating and many times a peculiar staring appearance of the eyes. The temperature is normal or frequently below normal, which is contrary to the fact in contagious diseases. The breathing is usually irregular and jerky. The acute cases invariably die after a course of 12 to 72 hours and are usually the first animals to be affected after moldy food is eaten.

"In sub-acute cases the symptoms are similar to those in acute cases but they do not come on so suddenly and are less violent. The sub-acute cases occur among animals that have eaten less of the poisonous food and they are the last to show symptoms. Dullness and difficulty in swallowing, 
associated with slobbering and dropping partially chewed cuds of food into the manger and feed box, are early signs of the disease. These are followed by increasing paralysis, especially of the limbs, weakness, and often indications of delirium. In fatal cases death follows in from several days to a couple of weeks. A few of the less severe cases may recover.

"The length of time between the feeding and the appearance of the symptoms, the suddenness of the attack and its duration, depend upon the amount of poisonous food taken. The course is shorter, from 2 to 4 days, the attack is more sudden and death soon follows in from 12 to 36 hours when large quantities are consumed.

"Prevention. Since horses and mules are very liable to poisoning with moldy foods where cattle may eat the same foods with little or no danger, the method of preventing the disease is clear. Under no circumstances feed horses or mules ensilage that is in the least molded or decayed. In feeding ensilage to cattle do not put it or scatter it where horses or mules can get to it, for they will sometimes eat the leavings in the feed trough after the cattle have picked out the best food. Do not throw waste ensilage where horses or mules can reach it. Sweet ensilage is a wholesome food for horses and of known nutritive value, but unless it is certain that it is perfectly fresh and free from mold it should not be fed to horses at all. Moldy silage has already caused such heavy losses on some farms that it will take all the profits a silo can bring to make good the cost.

"The hay, corn, oats and other grains fed to horses should always be of the best quality and the water troughs should be kept clean and the water pure and fresh. With all these precautions, forage poisoning can be eliminated." 
Settling. As has already been mentioned, the heavy fodder packed into the silo to a depth of from 30 to 50 feet settles rapidly for the first few days. In case the silo wall is smooth and vertical, the silage in settling does not draw away from the wall perceptibly, and there is no occasion for spoiled silage against the wall. If, however, the wall is not smooth, the silage will not come in contract with the surface of the wall in the recesses. These spaces will, of course, contain air, and the result will be moldy or decayed silage. In case a silo leans, the silage will settle a little heavier against one side and draw away from the other, thus allowing the entrance of air and consequent spoiling of silage.

It is sometimes reasoned that a silo should be built a little larger at the top than at the bottom in order that the silage will in all cases crowd the wall. On the other hand, it is sometimes reasoned that the silo should be smaller at the top than at the bottom, thus reducing the pressure of the silage against the wall when settling. Either of these two practices is poor, as the good of the one increases the danger that the other is designed to correct. In all cases the properly built silo is round, smooth, and plumb.

Material of the Walls. The material of the walls must be such that it will absorb as little moisture as possible. The wall absorbing no moisture would of course not admit air. The admission of air or the absorbtion of moisture will cause poor silage.

Strength and Rigidity. It is almost needless to say that the silo must have walls sufficiently strong to withstand the pressure of the silage, and should, of course, likewise be rigid enough to stand the action of wind.

Fire Exposure. Placing a wood silo among the other farm buildings reduces the distance a fire would need to jump in order to connect with other buildings. It is not only 
exposed to destruction itself, but it also increases the danger of fire spreading from one building to another. Ordinarily, silage is not materially damaged by fire, but it is exposed to decay after the silo is burned.

On the contrary, a masonry silo built of concrete or clay blocks is not subject to serious danger of damage by a fire. Moreover, it does to a certain extent serve as a fire wall between other buildings, actually interfering with the spread of fire from one building to another.

\section{FROZEN SILAGE}

Extent of Loss. The problem of reducing the quantity of frozen silage is very important with every silo user. Frozen silage is not necessarily a loss, but it is often a serious inconvenience. When thawed and fed soon after, it is practically as good a feed as before it was frozen. The loss comes from allowing it to stand exposed to the air too long after it is thawed, causing it to rot. Thus the danger of loss depends upon the amount of frozen silage that is allowed to accumulate. In most cases if frozen silage is taken from the wall each morning and piled in the center of the silo it will be thawed out by night. This of course depends largely upon the severity of the weather and whether or not the roof is tight and the door is kept closed. There is always sufficient heat in the main mass of silage to thaw the usual amount of silage frozen over night, provided this heat is not allowed to escape through a poor roof or open door.

How Heat is Lost. Heat may be lost from a silo in two ways. One is by conduction away from the silage through the wall. Plainly the amount of this loss will depend largely and directly upon the kind of material of which the silo is brailt. 
Heat is also lost by convection, which is the carrying away of heat by the circulation of air from the surface.

The best kind of house would be uncomfortably cold in the winter if it had no roof or if the doors were left open; it is just as true of the silo. If the doors are open or the chute poorly constructed, much cold air comes in and warm air escapes. This is particularly true of a poor roof or no roof at all. These two losses of heat combine at the surface near the wall to make the freezing most serious at this point. Also, it happens that this point is farthest away from the main body of the silage. Therefore heat reaches it more slowly, and the result is more serious freezing at that point than elsewhere.

Prevention. Generally, a few inches below the surface there is little, if any, frozen silage near the wall. In view of these facts, two-thirds of the freezing of silage can be prevented by simply keeping the outer eighteen inches of the surface of the silage beveled down toward the wall. Thus the silage most likely to freeze is removed before it has time to freeze. During warm or moderate weather the silage surface should always be kept level, but when the silage begins to freeze, the surface should always be beveled near the wall. Absolutely no silage should be allowed to cling to the wall of any silo.

The roof should always be made tight, and the following pages will show how every roof can be made so. Also, the doors should be kept closed when practicable. If that is impossible, it is doubly important that the chute be well built and kept closed.

The loss of heat from the surface, due to allowing the silage to stick to the walls, is much greater than the loss of heat out through the walls themselves. So the difference in materials of which the wall is made is of very much less 
importance than has usually been supposed. As will be seen in the following paragraphs, air does not conduct heat away from silage as rapidly as building materials; therefore, as little material as possible should extend continuously from the inner to the outer parts of the wall. Air spaces are of considerable advantage, and the larger the percentage of air space the better. However, it is very questionable if a man who must be careful of his dollars can afford to let this question of warmth influence his choice of materials to any great extent.

So many conditions enter into the question of freezing silage, that it is very difficult to form any conclusion without examining carefully a large number of silos which have been cared for in a similar way, having similar good roofs, doors, and chutes, and which are similar in exposure to cold winds, and are fed down to about the same place, at about the same rate. It is very doubtful in the mind of the writer whether or not there is much difference to be found between the loss of heat through a 2-inch stave wall and through a 6-inch concrete wall. The hollow wall, such as cement block, clay block, and monolithic concrete, has some advantage, but it is questionable if an 8-inch clay block wall is any better in this respect than a 4-inch. That is, the air spaces are not separate, and there is more material extending across the wall in the case of an 8-inch wall than in a 4-inch.

Air Spaces in Walls. It is always a good thing, so far as warmth is concerned, to prevent the circulation of air in the wall spaces. To illustrate, suppose the air space is vertical and the air free to circulate. When the silo is half emptied and the weather cold, the air is slightly warmed in the lower part of the wall by contact with the inner side of the wall next to the silage. This causes it to rise, carrying heat from the silage up to the colder parts of the walls at the top of the 
silo. The cold air falls, thus the circulation continues to carry away heat from the silage. If the circulation of air is restricted by horizontal partitions, this circulation and consequent loss of heat does not occur.

In double-wall wood silos, it is often well to provide for circulation at times. After the silo is emptied, air can be allowed to circulate in the walls, thus drying them and preventing rapid decay, which would otherwise occur. This, however, is not the case with masonry silos. There seems to be no advantage of air circulation in the walls of masonry silos, and there certainly are very marked disadvantages.

Influence of Materials. Materials differ in the ease with which heat passes through them; or, as it is generally stated, there is a difference in their conductivity. Aside from this, about the only general law of heat transfer which need be considered is that, other things being equal, the rate of heat flow through the wall will vary inversely as the thickness of the wall or the distance which the heat must travel. Heat will pass through a 1 -inch wall twice as rapidly as through a 2-inch wall of the same kind. Also, the content of moisture increases the conductivity of most materials, because the pores of the material contain moisture instead of air, and air is a poor or slow conductor of heat. Thus it will be seen that while dry wood is a very poor conductor, wet wood conducts heat very much more rapidly.

Although there are several other features in silo building more important, it seemed advisable to explain this matter of freezing in order to correct the misunderstanding that a 2-inch stave silo is so much warmer, or is so much less subject to freezing, than a thicker masonry wall. The actual facts do not bear out any such impression as this. In fact, about the only way to secure marked improvement in this respect is to build two walls entirely separate and if possible 
restrict circulation. It is, however, very doubtful if the average man can afford to spend very much money for the slight advantage to be realized in this way.

In the handling of frozen silage it is always best to remember that a preventative is better than a cure. Frozen silage is not a good feed any more than snow is a good drink, and will cause trouble; therefore silage should not be put in the troughs during cold weather any length of time before the stock is turned in to eat, and never should the silage be put into troughs which are already half filled with snow. The frozen silage which does occur should always be spread out in the center of the silo and covered lightly with other silage. This will usually remove the frost before evening feeding. 


\section{CHAPTER III WOOD SILOS}

The wide distribution and cheapness of lumber during the early stages of silo development were conducive to its extensive use. A very large proportion, 80 to 90 per cent, of all the silos in use are wood. Lumber and its uses have been more widely known to average mechanics, which also contributes to making the wood silo the most common type. It can be secured in convenient forms of good grade, and is quite durable if used properly. Wood swells quickly when in contact with the moist silage, which makes it an important and very useful silo-building material.

Kinds of Wood. Practically all authorities are today agreed that the various woods related to cedar, such as cypress, California redwood, and Oregon (Douglass) fir, are the most desirable kinds for silo purposes. There is room for choice among these woods, as cypress, while extremely durable, cannot be secured in as clear and long length stock as the redwood and fir. The redwood is more expensive than the fir, but it also is considered superior to it. It can be secured in a very clear quality and in any length required. The fir can also be secured in good quality and long lengths.

A good quality of white pine is very difficult to get today. Hemlock is not used a great deal, but for cheap silos a yellow pine or tamarack serves very well. The heartwood of the yellow pine or tamarack is very durable, and whenever possible clear heartwood should be secured.

Painting Wood Silos. With any kind of wood it is mportant, at least for the sake of appearances, to paint 
the outside. There is some question whether or not paint on the outside increases the life of the silo, as the moisture and heat on the inside cause the inner surface to decay rapidly.

Some paints, such as creosote, not only protect the wood from moisture, but also are poisonous to the microscopic plants which cause decay, thus preventing decay, if the wood is thoroughly saturated. This is accomplished by means of heat and pressure. It will undoubtedly increase the lasting qualities of the silo if the staves are merely painted. This should be done, however, after it has been delivered on the farm, as the farmer can then determine

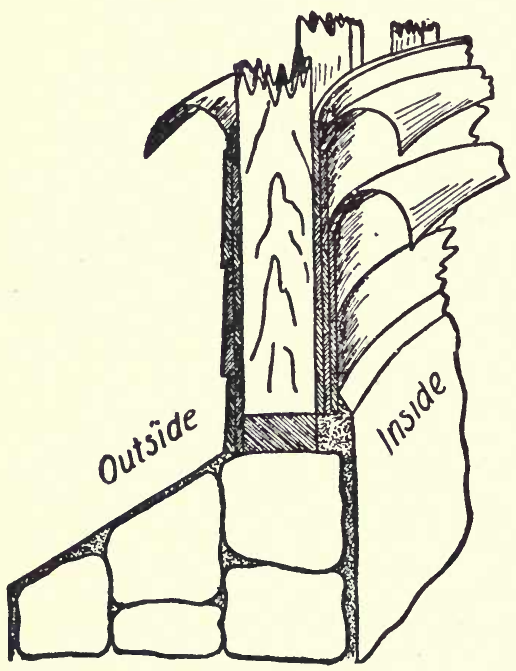

Fig. 3. The construction of the Wisconsin silo. the quality of the wood before painting. It is better to paint the staves before erecting the silo, as the joints can then be thoroughly covered.

Frame Silos. The first wood silos were square frame structures studded vertically and sheathed horizontally. In the development of the round silo it was only natural to follow the same plan, using lumber thin enough to bend conveniently. Perhaps the best known of this type of silo was originated by F. H. King, of the Wisconsin experiment station, in the '80's. The lumber extending around the siln has suf- 
ficient strength to prevent the silage from bursting it. Generally one thickness of siding was placed outside, and two or three thicknesses with tar paper between were placed inside. This construction is plainly shown by Fig. 3, taken from an early Wisconsin bulletin. H. B. Gurler, of DeKalb, Illinois, substituted lath and plaster for the inner sheathing of the Wisconsin silo. It was originally designed for use inside of the barn and has been more successful there than outside. This silo has been quite popular, especially in Illinois. In recent years the quality of lumber found on the market has decreased considerable, so that it is now difficult in many localities to secure at a reasonable cost such quality of lumber as can be bent for circular sheathing.

The Wood Hoop Silo originated in the western part of New York, and is shown in Fig. 4. The first silo of this type that the author has been able to learn of was built in 1894, by J. T. Wells, a builder and contractor of Scottsville, New York, and had a continuous door. This silo has several advantages over the Wisconsin silo in that the sheathing is not circular and only enough lumber is bent around to prevent the silo from bursting open. Common flooring is used for sheathing and is nailed vertically on the inside. Where better work is desired, it is also sheathed on the outside; this gives a hollow wall. The silo is nailed together so that, as in the case of the Wisconsin and Gurler silos, there is nothing to tighten or loosen at any time. It is made entirely of standard lumber. If necessary the hoops can be made of weather boarding. Braces are placed between the hoops for jambs, and at the door 2-inch material is placed vertically between the hoops. The hoops are generally placed 3 feet apart, and all are of such size that the pressure will be taken care of. Fir, white pine, or cedar siding may be depended upon to withstand a pull of from 1400 to 1800 pounds per 

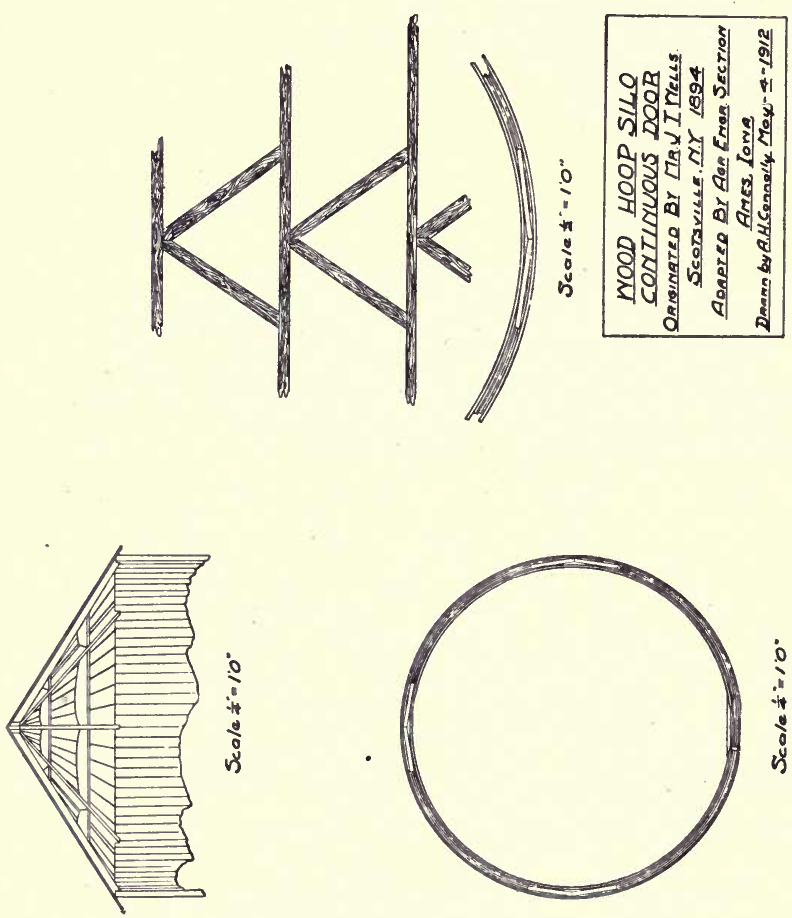

0
$\vdots$
$\vdots$
$\vdots$
0

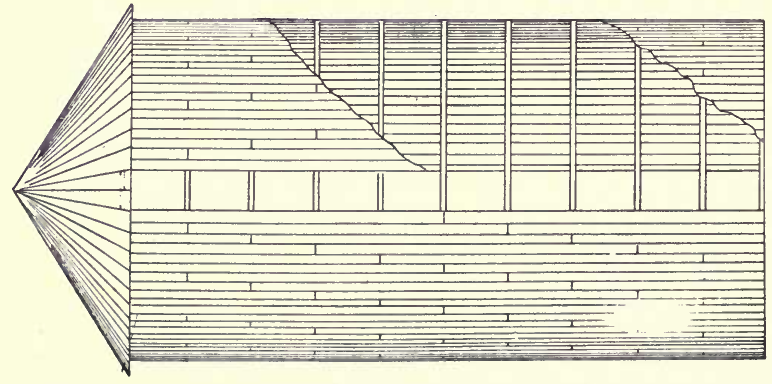

:0 
square inch, so that for a $16 \times 30$ silo the hoops should be approximately 3 inches square. This size is necessary at the bottom in order to stand the pull, and the same size should be used at the top, so that the hoops will be large enough to brace the silo wall. This silo is not very widely used, but seems practicable in a very wide range of conditions, and in the opinion of the writer is destined to become one of the very popular wood silos.

Stave Silos. The stave silo is commonly called the tub silo, and is ordinarily made of $2 \times 6$ tongued and grooved staves held together by hoops made of steel rods, joined at the ends by means of malleable iron lugs and

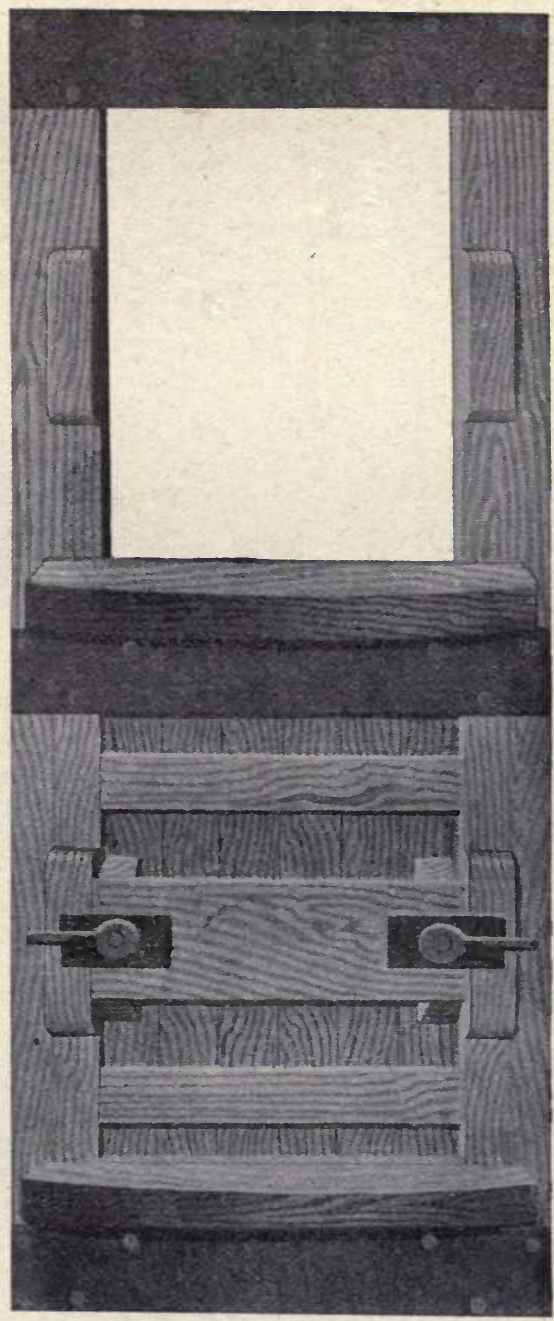

Fig. 5. The independent door. 
nuts. Originally this form of silo was used only with individual doors, that is, doors placed between every other pair of hoops. At present a great many companies are mak-

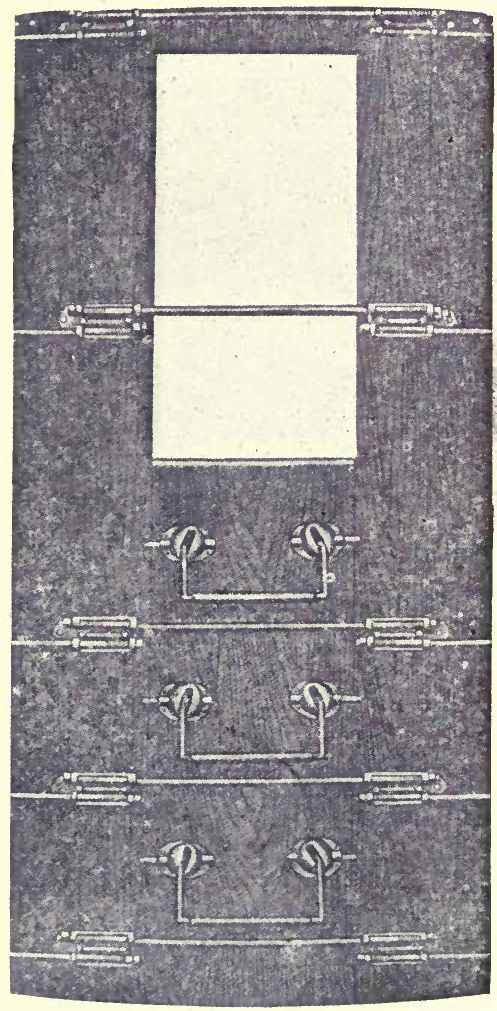

Fig. 6. The Unadilla door. ing the continuous-door stave silo, differing only in minor features of the door frame. Several of these are shown in order to illustrate the different kinds. A great advantage of the stave silo is the rapidity with which it can be built. It requires only one or two days for erection. That it is a moderate priced silo, portable, and has a capacity to resist wind as successfully as some of the other types, are also advantages.

If the silo is secured to the foundation and the top guyed by means of three or four wires, ninetenths of the difficulty of blowing down can be done away with. It should be secured at the bottom to the foundation at four to six places, and the guy wires should extend out quite a distance or across to the framework of the barn. They should never be placed close to the foot of the silo and 
never steeper than 45 degrees. For silos twelve feet or over in diameter, the stave should be 2 inches thick and 4 to 8 inches wide, the most common width being 6 inches. In the case of silos 12 feet in diameter or less, they have, in some localities, been built from 1 -inch flooring and the ends of the flooring joined together by steel splines. The 1 -inch stave is quite economical, and for small silos has been found very successful.

In the care of the stave silo it is necessary, of course, as it becomes empty and dried out, to tighten up the guys and the hoops. Sufficient threads are provided for this so that it can be accomplished very easily. One of the most common mis-

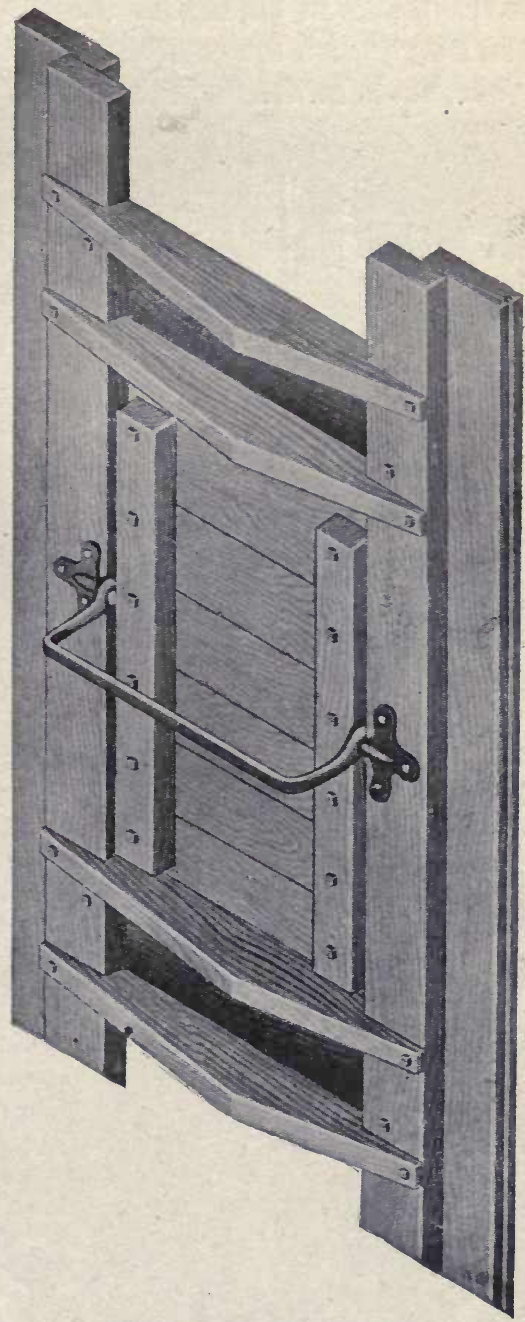

Fig. 7. The Indiana door. 
takes made in caring for the silo is to neglect to loosen the hoops when the staves swell after the silo has been filled. This should be attended to; as soon as the silo tightens up the

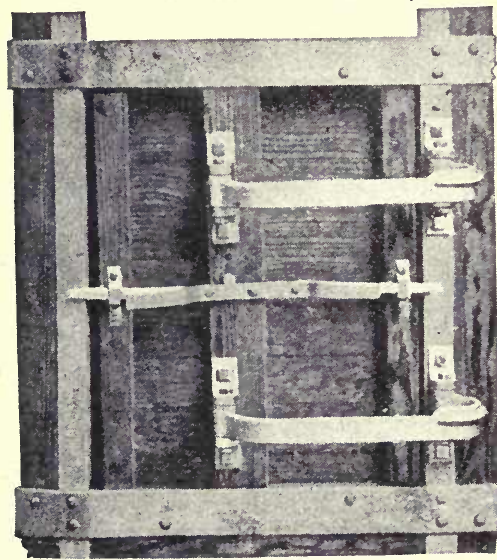

Fig. 8. The hinge door. hoops should be let out to the same point where they were when they were originally erected. The paint on the ends of the rods will indicate this point, or it may be marked by means of a punch. If this is not done the door-jambs will be crushed together, the edges of the staves crushed, and the lugs broken or at least bent seriously. It requires only a few years of neglect in this way to use all the threads on the hoops. Then the silo can not be further tightened without washers or short pieces of gas pipe under the nuts. 


\section{CHAPTER IV \\ MASONRY SILOS}

Advantages and Disadvantages. Masonry and steel makes a successful and permanent silo when properly used. The chief advantages are permanence and the slight amount of care necessary. The disadvantages are the length of time required to build and the difficulty of getting men properly skilled in this kind of work. It is necessary, as with any other silo, to use sufficient material to prevent the pressure of the silage from bursting the sides. Masonry alone cannot be depended upon to withstand this pressure, and steel must be applied in the form of wires and rods to withstand this tension or outward pressure. In order that the steel may be as permanent as the masonry, it must be protected from the air by at least an inch of mortar or concrete.

Quality of Materials. It is necessary, in the use of masonry, to use only such material as will be practically air tight; that is, it must not be capable of absorbing water to the extent of more than one-tenth to one-twentieth of its own weight. In case the masonry silo is found to be faulty in this respect, it can be improved by plastering the inside with good rich plaster, or covering with coal tar, creosote, or similar substance.

It is a poor plan to make one link of a chain weaker than the others; it is likewise foolish to build one part of a silo less permanent than another. Wood door frames are less permanent and more expensive than masonry, and often cause leakage of air between the door frames and the wall. To do away with this difficulty, it is simply necessary to mold concrete door frames to receive the doors. The only logical 
roof for the masonry silo is masonry. It is easy to build it either of concrete or clay products, and then it becomes fully as permanent as any other part of the silo.

Stone Silos. The use of stone silos is naturally confined to localities where stone is plentiful; and probably the greatest number of these stone silos are to be found in Wisconsin. The cost of material under favorable circumstances is very slight, in fact almost nothing when it must be gathered from the field to permit cultivation. The labor feature is an important factor, and as the cost of labor increases, the building of stone silos decreases.

It was common to depend upon very thick walls to withstand the outward pressure, but, as already stated, it is never safe to depend upon masonry to withstand any force which tends to pull it apart. Where liberal amounts of steel have been placed in the wall they have not cracked, and where they have been plastered inside with a good cement plaster they have made very satisfactory silos.

Concrete Silos. With the advent of concrete, and especially reinforced concrete, it was only natural that it should be tried for silos. It has been used in many different ways in monolithic construction (molded in place in forms) with both single and double wall, and is also made into silo blocks of different kinds. It is difficult to say just who was the first to use concrete for silos, or even in which section of the country this use of concrete originated. But today it is successfully and very widely used.

Like the stone silo, the advisability of using it depends very largely upon the supply of material; that is, gravel or crushed stone. It has been found durable for all climates, is storm proof and fire proof,-in fact it is difficult to see how anything could be built more permanently. Double walls are advantageous in resisting frost. This form of construc- 
tion can be made to embody all of the essentials of silo construction. The precautions to be taken are to secure competent workmen, thorough reinforcement, and properly mixed concrete.

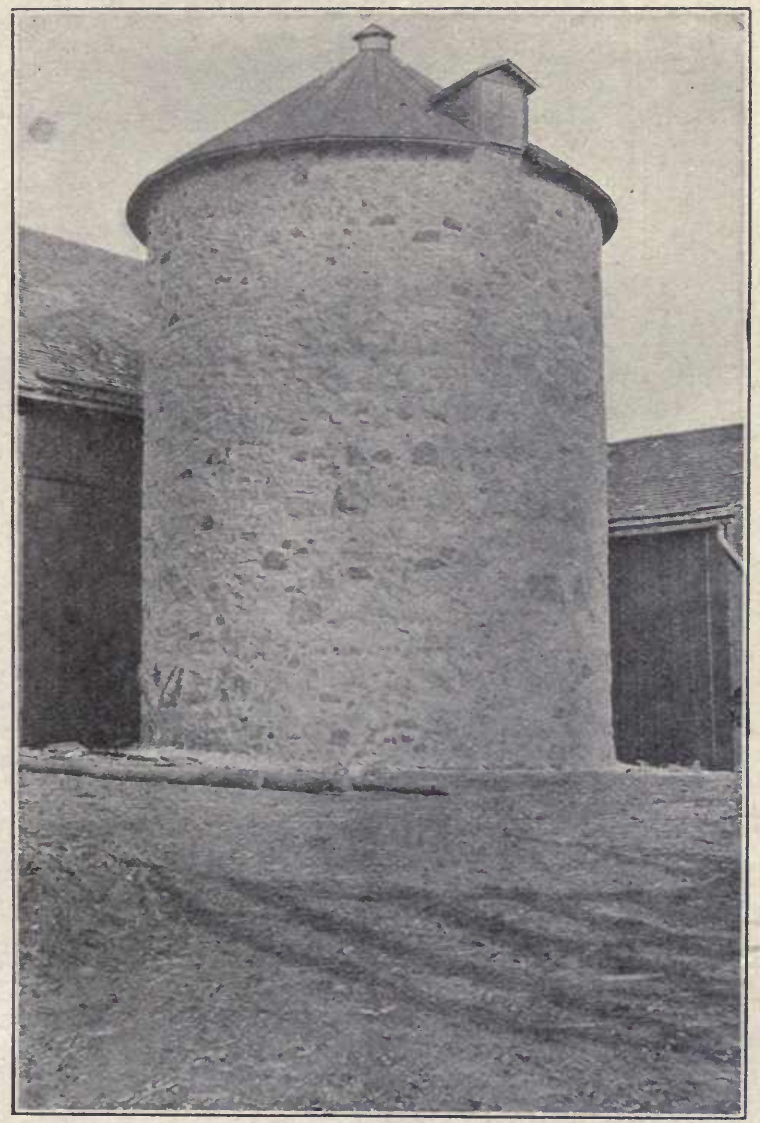

Fig 9. The stone silo. 


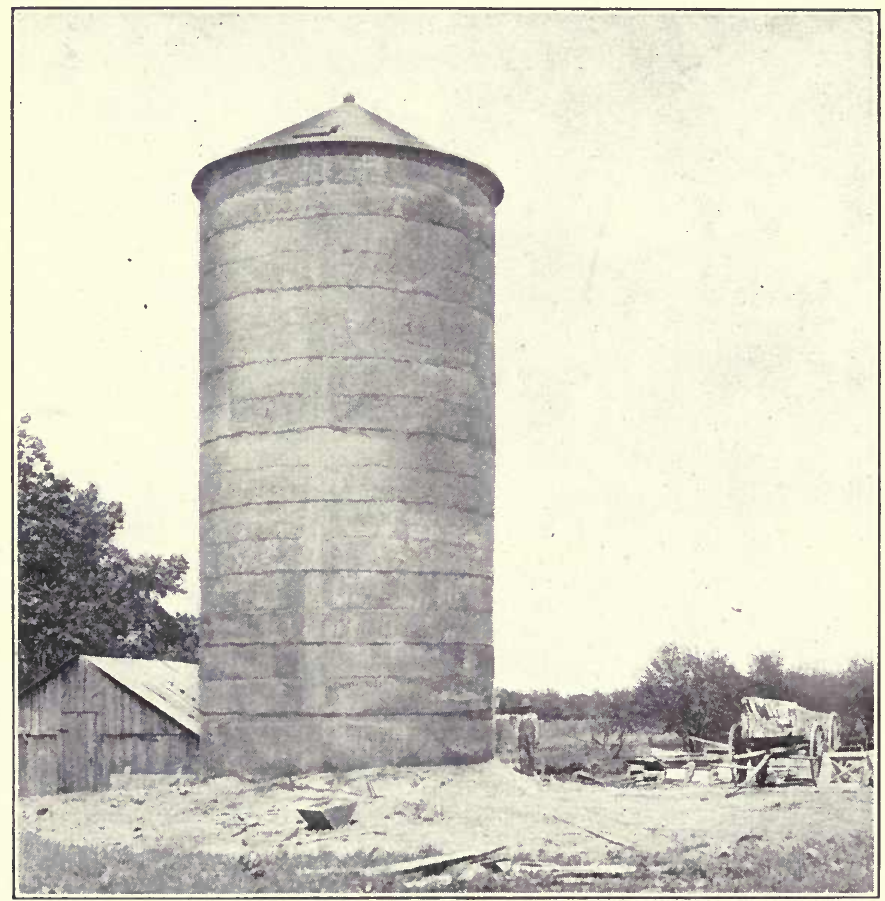

Fig. 10. A concrete silo, constructed under the supervision of the Nebraska experiment station.

Plastered Silos. A modification of the concrete silo that has come into more or less prominence in some localities in the last few years is the plastered silo. Its essential feature is simply a skeleton of expanded steel used as reinforcing. This steel is covered with two or three coats of plaster on each side, so that when complete it is 2 or 3 inches thick. It is necessary to use as much steel, or more, in this construction than is indicated in the reinforcing plate shown on page 78 , 
and in addition a scaffold for temporarily holding the steel in position is required.

Clay-Product Silos. The economical masonry building materials of the present time may be divided into two general classes, concrete or stone, and clay products.

Either of these classes furnish excellent building materials for silos. Therefore it is only natural that in many places brick was used in the early development of the silo. As in

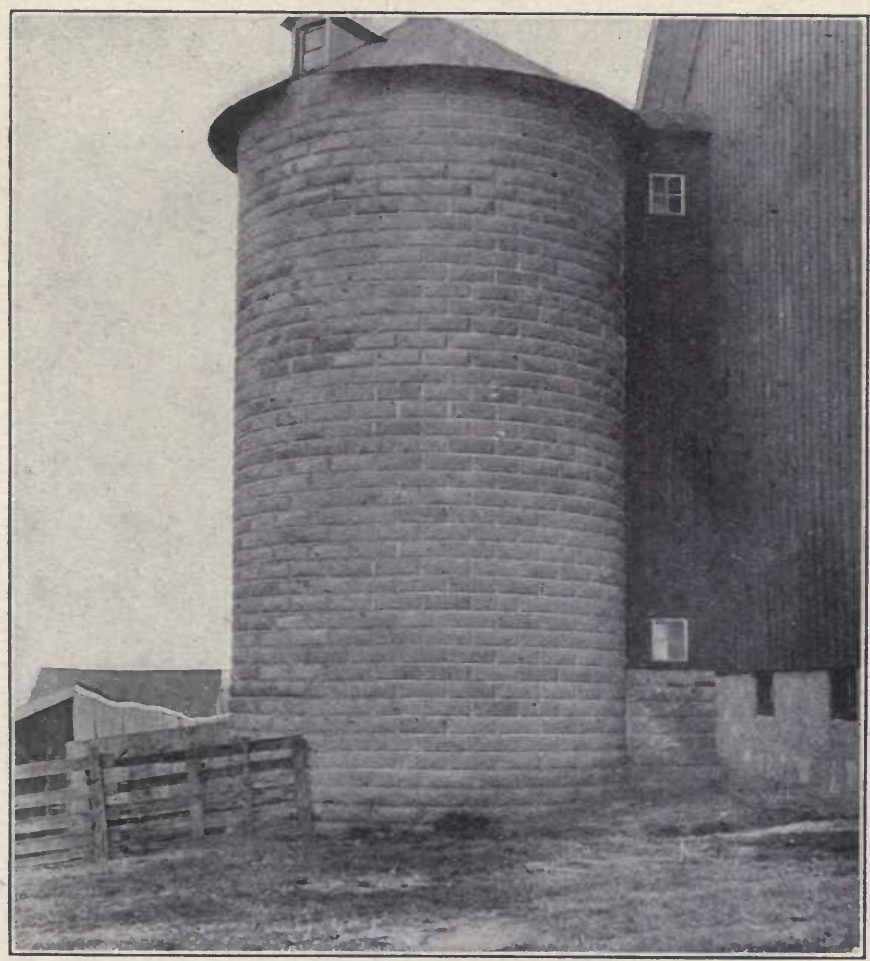

Fig. 11. The cement block silo. 
any other masonry material, the outward pressure must be taken care of or resisted by steel placed in or around the wall, preferably in the wall, as it is then protected from rust. In the earlier forms of this silo, as in the concrete and stone silos, wooden door frames were used.

As already suggested, the choice between clay products and concrete will usually depend upon the local conditions and the supply of these materials. Therefore, it was only natural, while collecting material for the publication of Bulletin 100 of the Iowa Agricultural experiment station, that the author put forth an effort to design a successful, economical, and durable silo for localities in which materials for concrete construction were scarce and expensive. From this effort has resulted the Iowa silo, described in Bulletin. 117, the distinguishing features of which are a reinforcing system and a door-frame design for bricks or blocks, either clay or cement. The fact that it was developed in portions of the state where concrete material was scarce, resulted in almost exclusive use of hollow clay blocks or building tile.

The door frame was built of reinforced concrete, molded in the form of either individual or continuous doors. A special and simple reinforcing system was designed. The door jambs are reinforced vertically and are tied together across the door opening by a half more steel than is used in the same height of the wall. Heavy wire is used in the mortar joints extending around the silo and secured to the vertical steel in the door jambs. Considerable time and effort were spent upon the development of a convenient scaffold, modifications of which are used by most of the Iowa silo builders. Atpresent this silo has established itself as one of the economical and practical types of silo in use. Like any other silo the general precautions to be taken are to 


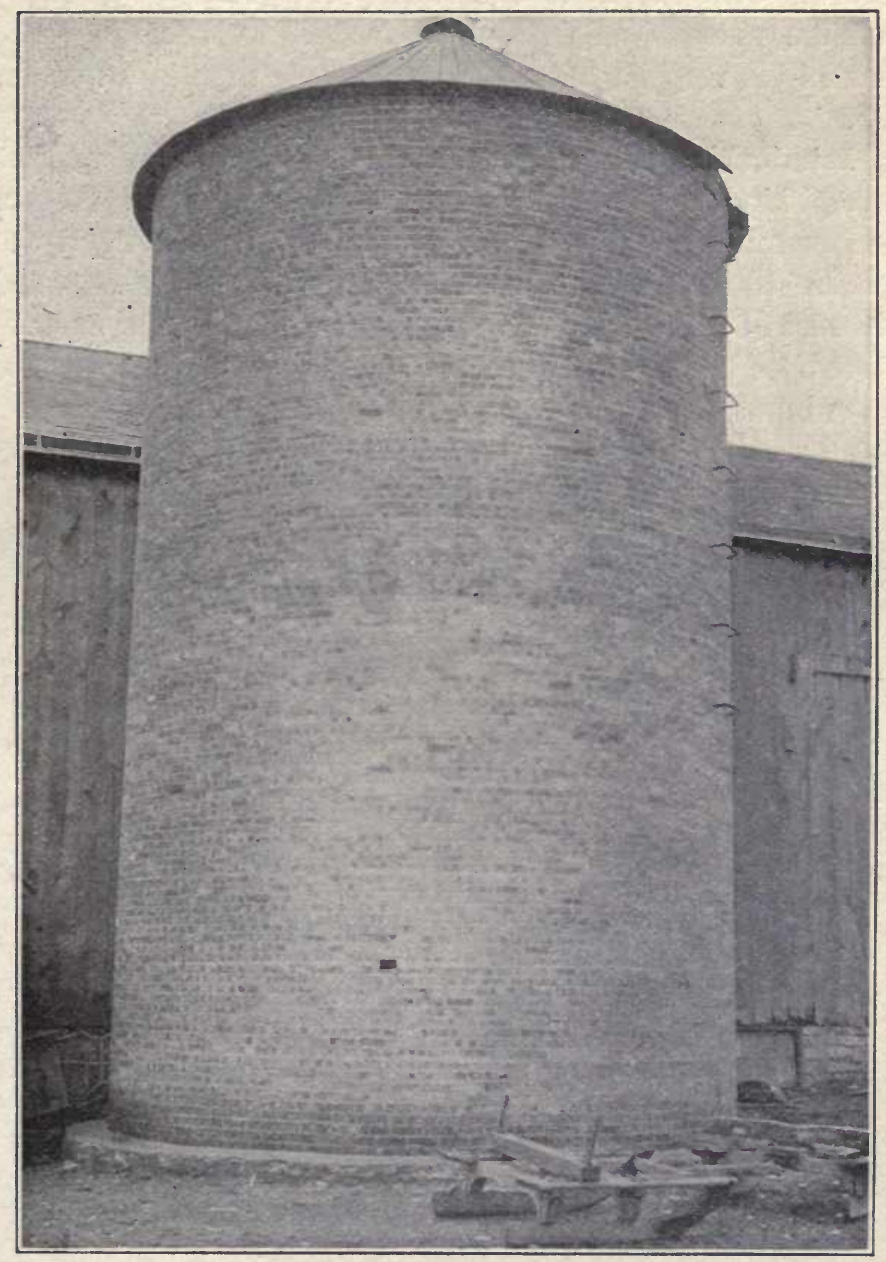

Fig. 12. The old brick silo. 
secure good material and have it put together in a workmanlike manner, as in any other masonry silo the workmanship is very important, even more so than in a wooden silo.

Interlocking Block Silos. There are on the market several kinds of interlocking devices for silo building blocks. In general this depends, in one way or another, upon the tensile strength of the blocks taking care of the outward pressure of the silage. If the proper amount of steel is used, these silos become safe; otherwise, too large a percentage of them burst, as masonry can not be depended upon to withstand a pull. If a sufficient amount of steel is used the interlocking devices become an unnecessary expense. 


\section{CHAPTER V}

\section{PLANNING THE SILO}

Selecting the Location. One of the first questions concerning location is, Shall the silo be placed inside the barn, or not? It is very seldom that there is an occasion for placing the silo inside the barn. There are good reasons for this:

First, the silo, with the exception of a few types, is of such construction that it does not need the protection of a covered building.

Second, it is not economical to place a silo in a building where it will occupy space which may be put to other use.

Third, a silo located inside of a building is often unhandy to fill. The forage cannot be delivered to the cutter conveniently.

Fourth, by locating a silo outside of the building and connecting it thereto with a passage provided with doors, the objectionable odor of the silage may be kept out of the building.

In general, it seems that there are few advantages in building a silo inside of a barn, and many in building it outside. There are types of barns, however, the large round barn for instance, which make it possible for a silo to be conveniently located at the center.

There are other considerations concerning the location of the silo which should be taken into account. The convenience in feeding is one of the most important. It is ordinarily most convenient to place the silo just outside the barn and directly connected to one end of the feed-way or feed room. Thus a cart or litter carrier may be loaded with silage and 
pushed along the aisle, making a convenient method of distribution. If yard feeding is practiced, the carrier can be arranged to run over a line of bunks. In this case the silo would probably not be placed facing the barn. If silage is fed both inside and outside, the carrier can be arranged to run both ways. Sometimes part of the silage will be fed in the barn and the rest carried in a wagon to the feed boxes. This is the case on many general stock farms. Then the silo should be placed far enough from the barn to allow a wagon to be driven under the chute, thus loading it conveniently. Large doors can be provided on each side of the passage, so that while feeding in the barn one does not need to go out doors to get the silage.

Often, after giving these matters thorough consideration, there is still an opportunity for choice with reference to exposure to weather or the location of the silo in relation to the general group of buildings. Other things being equal, it is well to place the silo where it will be protected as much as possible from the north and northwest winds and from exposure to the sun. In the case of light wood or stave silos, it is often of the utmost importance to place the structure so that it will be protected from the stronger summer winds. This can often be done by locating it back of groves or in the $\mathrm{L}$ of the barn.

The question of general appearance of the farm buildings is too often neglected. This should be only of second consideration, as there is beauty in utility. Often the upper portion of a well-built silo showing above the sloping roof of some of the other buildings adds very materially to the general appearance of the group of buildings. Also the side near the top often affords the best place for the farm name. 
Cost Considerations. The question of cost must be viewed from every possible angle. First, perhaps, is a consideration of the financial affairs of the prospective builder or purchaser. Lack of money should never be a reason for going without a silo. Properly used, it will put a farmer in far better condition to meet his financial obligations than before. It does, however, often happen that a man is loaded so heavily with financial obligations that it does not seem advisable to assume more debts. Yet under these circumstances it might also happen that labor and help could be secured from the neighbors, with the understanding to repay it in labor in the future. In such circumstances it is clear that the cash outlay for material becomes of the first importance, and cost of labor becomes second. To illustrate, a man in such circumstances might have gravel on his farm. Also, he might have lumber which he could use temporarily for the scaffold. The cost of cement block molds is slight, and if this man were somewhat of a mechanic he would find it advantageous to secure a mold or molds and make his own cement blocks at odd times. In this way a cement block silo could be built with less cash outlay than any other form of silo. In most cases, however, it would be necessary, in considering cost, to figure the cost of the labor of making the blocks, etc., so that for the man who must consider time as money, or who would realize immodiate cash returns for his time, some other type would be a better investment for him. In such a case the cash outlay might not exceed $\$ 150$ for a $16 \times 40$ silo, while the cost of all material and labor might exceed $\$ 400$.

In considering the cost of material it is evidently important to take into account the amount of material that must be purchased, also the amount of material that may be furnished from the farm itself. In furnishing such material, 
however, it should not be figured as costing nothing simply because there is no cash outlay, but it should be considered at its market value. The same is true of labor, which many times is not figured in because money has not been paid. This is not only a poor way of figuring, but it is extremely misleading when costs figured in this way are reported to the press or in any other way to the public.

Two classes of material are required in building a silo; namely, that which becomes permanently a part of the silo, and he falsework and other equipment, scaffold, forms, hoisting apparatus, etc. If these are furnished by the contractor or can be sold or rented subsequently, this cost should not, of course, be charged to the silo.

In regard to the quantity and cost of labor, it is important to remember that labor can not be figured on definitely for several reasons, unless it is contracted. Then the contractor assumes the responsibility, and the farmer pays for being relieved of the same.

The question of the efficiency or perfection of the silo is of course primarily important. However, each type shown in this book, is, when properly built, very efficient. Any of them properly built and filled will preserve silage with practically no unnecessary loss, so that it becomes a question of first cost, durability, and probably cost of repair and care. The silos requiring paint or other attention should be charged up with that item. In any building the cost of repair becomes important, and one should consider the cost of repairing different parts, and the probable length of time before such repair will be necessary. Finally, the rate of depreciation must always be considered.

The amount of investment may be considered as the sum necessary not only to cover the first cost, but also to provide a sinking fund of enough money put at interest to furnish 
cost of care and repair permanently, and to have accumulated enough by the time the original building ceases to be useful, to replace it. In order that such an investment shall be good, it must produce not only interest but profit upon this original cost and so-called sinking fund.

Planning the Size of the Silo. The best general advice as to the dimensions of silos is to build them small in diameter and great in height. The diameter must be such that at least 2 inches can be fed from the silo each day. The following tables will serve as the basis from which the amount of

Table I. Capacity of round silos.

\begin{tabular}{|c|c|c|c|c|c|c|c|}
\hline $\begin{array}{c}\text { Inside } \\
\text { diameter }\end{array}$ & Height & $\begin{array}{l}\text { Capac- } \\
\text { ity, } \\
\text { Tons }\end{array}$ & $\begin{array}{l}\text { Amt. to be } \\
\text { fed daily. } \\
\text { Lbs. }\end{array}$ & $\begin{array}{c}\text { Inside } \\
\text { diameter }\end{array}$ & Height & $\begin{array}{l}\text { Capac- } \\
\text { ity, } \\
\text { Tons }\end{array}$ & $\begin{array}{l}\text { Amt. to be } \\
\text { fed daily. } \\
\text { Lbs. }\end{array}$ \\
\hline 10 & 28 & 42 & 525 & 16 & 28 & 108 & 1340 \\
\hline 10 & 30 & 47 & 525 & 16 & 30 & 119 & 1340 \\
\hline 10 & 32 & 51 & 525 & 16 & 32 & 131 & 1340 \\
\hline 10 & 34 & 56 & 525 & 16 & 34 & 143 & 1340 \\
\hline 10 & 38 & 65 & 525 & 16 & 36 & 155 & 1340 \\
\hline 10 & 40 & 70 & 525 & 16 & 38 & 167 & 1340 \\
\hline 12 & 28 & 61 & 755 & 10 & 40 & 180 & 1340 \\
\hline 12 & 30 & 67 & 755 & 18 & 30 & 151 & 1700 \\
\hline 12 & 32 & 74 & 755 & 18 & 32 & 166 & 1700 \\
\hline 12 & 34 & 80 & 755 & 18 & 34 & 181 & 1700 \\
\hline 12 & 36 & 87 & 755 & 18 & 36 & 196 & 1700 \\
\hline 12 & 38 & 94 & 755 & 18 & 38 & 212 & 1700 \\
\hline 12 & 40 & 101 & 755 & 18 & 40 & 229 & 1700 \\
\hline 14 & 28 & 83 & 1030 & $\begin{array}{l}18 \\
18\end{array}$ & $\begin{array}{l}42 \\
44\end{array}$ & $\begin{array}{l}240 \\
264\end{array}$ & $\begin{array}{l}1700 \\
1700\end{array}$ \\
\hline 14 & 30 & 91 & 1030 & 18 & 46 & 282 & 1700 \\
\hline 14 & 32 & 100 & 1030 & & & & \\
\hline 14 & 34 & 109 & 1030 & 20 & 30 & 187 & 2100 \\
\hline 14 & 36 & 118 & 1030 & 20 & 32 & 205 & -2100 \\
\hline 14 & 38 & 128 & 1030 & 20 & 34 & 224 & 2100 \\
\hline 14 & 40 & 138 & 1030 & 20 & 36 & 243 & 2100 \\
\hline & & & & 20 & 42 & 300 & 2100 \\
\hline & & & & 20 & 44 & 320 & 2100 \\
\hline & & & & 20 & 46 & 340 & 2100 \\
\hline & & & & 20 & 48 & 361 & 2100 \\
\hline & & & & 20 & 50 & 382 & 2100 \\
\hline
\end{tabular}


feed used daily, and the amount which should be used from a silo of any size, may be estimated. These tables are taken from Bulletin 100, Iowa agricultural experiment station, Table II being furnished by the Animal Husbandry Department of the Iowa State College.

Table II. Amounts of silage required per day for various kinds of stock.

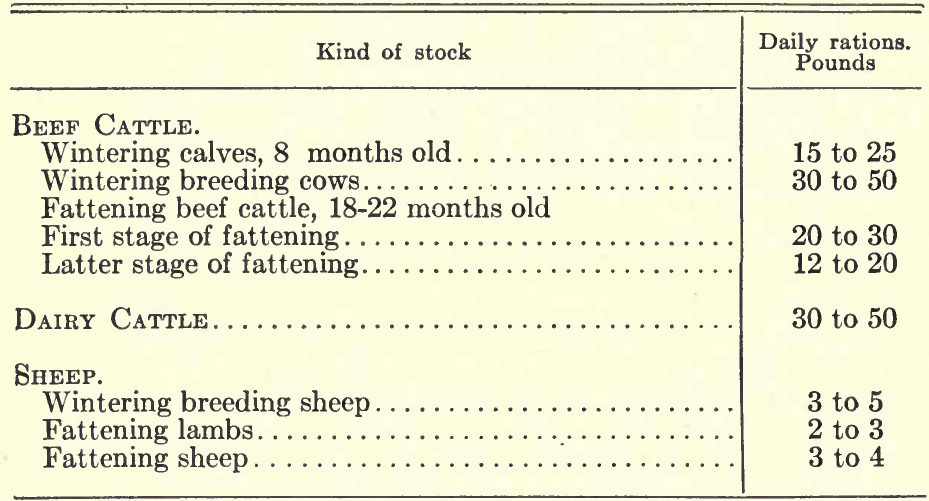

Table I may be used in connection with Table II to determine the size of silo needed to fulfil various conditions. For instance, if the silage is to be fed to a herd of 40 dairy cattle, at the rate of 40 pounds per head per day, a silo 16 or 18 feet in diameter will be satisfactory. In case a smaller type of cattle were kept, they would eat about 30 pounds each amounting to 1200 pounds per day. As seen from the righthand column of Table I, this is not sufficient for a 16-foot silo; therefore a 14-foot silo should be used, unless somé young stock is kept in addition to the 40 mentioned.

It should be borne in mind that if the size of the herd is likely to vary from year to year, the diameter should be such that the smallest probable herd would still use 2 inches 
from the surface each day. In calculating the height, one must remember that the height should be such as to furnish the feed capacity for the maximum size of the herd during the required feeding season.

The feeding season will vary. In many cases the silo is not opened until Christmas time, and silage is fed as needed until grass, which is usually early in May. Oftentimes it is desirable to feed silage from filling time, the middle of September, until May 1. In many cases silage is fed every day in the year, and in most every case it is desirable to have silage to depend upon during the dry summer weather in August and September. Thus the feeding season varies from 130 to 365 days, and since at least 2 inches should be fed per day, for a 130-day season 22 feet or more (usually more) of silage will be consumed. The silage will settle at least onesixth, or approximately 16 per cent, depending upon the time spent in filling. This indicates that a silo should seldom; if ever, be built less than 30 feet in height. If any silage is not used at the end of the winter season, no harm is done, as it will keep and will be found very advantageous during the dry summer months. In case the herd is larger than usual or the feeding season longer, a silo 40 feet in height above the ground is not too large. Blowers of the ordinary kinds will handle corn for silos 40 or 50 feet in height without any difficulty.

The amount to be fed daily from the surface will vary somewhat with the condition of the silage and the time of year. The point is that no silage should be left exposed to the air long enough to permit the growth of mold. The air penetrates dry and poorly packed silage more rapidly than more moist and well packed silage. During the summer mold grows more rapidly than during the winter, so that the summer silo should be made small in diameter. In addition 
to the rapid growth of mold, if the cattle have some pasture they will not eat as much of the silage as they otherwise would.

At all times it is important to remove the feed evenly from the surface of the silage in order that no portion will be exposed to the air longer than necessary, not longer than a few days in winter nor longer than one day in summer.

Excavations and Foundations. Every building should rest upon a foundation broad enough to prevent appreciable settling, and deep enough to rest upon earth which is never disturbed by frost. Excavating all the earth to the depth of the foundation increases the capacity of the silo. This space, however, costs somewhat more than equal space in other parts of the silo, on account of the additional labor of excavation. Thus it will be seen that it is not economical to extend the foundation deeper than necessary to get below the frost.

In pits 14 feet or more in diameter, it is usually most economical to use a team and scraper in removing most of the dirt. In the case of monolithic concrete silos, the sides of the pit should be left smooth enough to serve as an outer form, if the soil is of such a nature as to permit it. For block silos the diameter of the pit should be such that the outer part of the silo wall will come within about 3 inches of the sides of the pit. This space gives room to work with the trowel, and should afterwards be filled in with concrete in order to protect the pit from soil water. It improves the appearance of the silo to carry this concrete up 8 or 12 inches above the level of the ground. This can be done very well by laying up blocks temporarily about three inches from the silo wall. These blocks make a very convenient form for the concrete and may be removed before the concrete is set thoroughly. In the case of a stave silo, it is 
questionable whether or not a pit should be used, as the concrete wall forms a shoulder inside of the staves,causing the silage to draw away from the staves as it settles. Also, there is usually a leakage of air between the staves and the foundation.

The foundation of the stave silo can usually be made most economically by simply digging a trench to the depth of 2 or 3 feet. This trench need not be wider than 6 or 8 inches but the foundation should be extended above the ground 8 inches or a foot. Usually thin lumber is bent around and secured to stakes set in a circle to make a form; but the stakes must not be driven into the ground until the pit is full of concrete, or the soil will be caved in.

In case a pit is deemed advisable, the earth should be dug out as soon as the hardening of the concrete will permit, as the inner part of the foundation may then be trimmed smooth with a spade and plastered, if desired.

Whether this pit is excavated or not, the foundation should be reinforced with considerable wire or enough steel rods to be the equivalent of at least a $1 / 2$-inch rod. The amount of steel necessary for this, of course, depends entirely upon the size of the silo and the distance which the foundation projects above the ground. If there is any question as to the quantity to use, the reinforcing table shown for masonry silos should be consulted, using the quantity that is called for in this table.

Drainage is important and should receive more consideration than is usually given in the construction of farm buildings, and especially of masonry silos. Any soil will support a greater load when dry than when wet. This is especially true of clay. The heaving motion of frost is due entirely to the moisture contained in the soil, which expands with an almost irresistible force upon freezing. Therefore, 
unless the foundation lies in dry, well drained soil, a drain tile should be used to remove the ground water. The tile may be located around the lower edge of the wall. If gravel or cinders are used, they should be well tamped before the foundation is put in place.

In the case of the wood hoop silo, the walls may be set flush with the inner part of the foundation of the silo pit, using a heavy coat of asphalt or tar on top of the foundation. The wood will then be protected from moisture of the foundation, also the joint between the wall and the foundation will be made perfectly air tight. In this case the pit is advisable.

In case gravel is expensive or scarce it may sometimes be economical to use brick or clay blocks for the foundation. If they are used exclusively for the foundation of a clay block silo, two 8 -inch blocks may be laid side by side, making the first course 16 inches wide. The next may be laid crossways, making a 12-inch course. The third may then be laid on edge, starting the 4-inch wall.

Details of Doors. In stave silos found on the market, very convenient doors are usually provided, so that little need be said concerning their construction. There will be found some difference in them, in that some are more nearly air tight, stronger, and less liable to stick than others.

For masonry silos, a cheap and very good door is shown in Fig. 28. This door as shown is made of two thicknesses of ship-lap that lap onto each other about two inches, and are not beveled at the ends. The boards on the outer side are shorter than those on the inside. A wide cleat with beveled edges is nailed to the inner side of the door, on which the different doors meet end to end, thus offering little obstruction to the free settling of the silage. 
In order that any silo may fulfil its purpose, it is necessary that the joints between the doors and the door frames be air tight. It is difficult to obtain air-tight joints between doors and masonry drawn out of shape, thus causing the loss of as much as 4 or 5 cubic feet of silage at one door. Sealing with clay was found to be satisfactory where reasonable care was exercised in its use. This becomes a very simple matter by taking a quantity of fine clay or other fine soil, wetting it until sticky but quite stiff, and filling the shoulder of the door frame with it before pressing the door into place. If the mud is rather stiff it will hold the door to place until the silage is up high enough to secure it permanently. The moisture of the silage keeps the clay damp on the inside, thus making it air tight. This is one of the oldest and best methods of sealing doors. It has been thoroughly tried and found to be very satisfactory.

Roof Plans. There is in some localities a general impression that a silo does not need a roof. In reality a roof is not absolutely necessary but is very desirable. It aids very materially in preserving the shape of a wood silo, and in any silo it is important to reduce the amount of frozen silage and to protect the feed from bad weather. Otherwise, with changes of weather the character of the feed will change.

In building a roof it is desirable to make as rigid a structure as is practical, at the same time obstructing the head room as little as possible. It is quite common to use timbers extending across stave silos from one side to the other. This is entirely dispensed with in the drawing shown in Fig. 4. A most economical roof for the wooden silo is generally made of rafters placed about 7 feet apart at the cornice and extending in to the center of the roof. Headers should be placed about three feet apart between these rafters. On a 16-foot silo roof with $1 / 3$ to $1 / 4$ pitch, the rafter will be not far from 9 feet in 
length, and two headers should be placed between each pair of rafters about equally spaced along the length of the rafter. These headers should be made of 2-inch material, and curved. To determine the curvature of these headers, take a radius equal to the distance from the rafter to the center line of the silo, measured on the line extending at right angles to the rafter at the point where the header is nailed to it. Then lumber should be bent around the silo for a frieze and the sheeting nailed securely to this, thus preventing the cold air from coming in.

The sheathing is most conveniently made from sound 12 or 14-inch barn boards ripped diagonally. These should be nailed to the headers and to the top of the silo wall, so that only the sheathing boards project from the cornice. By covering this with a good grade of prepared roofing, a good roof is secured. Dormer windows in the roof are quite popular and perhaps add something to the appearance of the roof, but are more expensive than the trap door and do not serve so well. A glazed sash used as a trap door will let in more light than the same sash used as a dormer window. It should be covered with quarter-inch meshed galvanized screen in order to protect it from hail.

The Chute. In order that the silage may be removed from the silo conveniently, it is essential that a chute or vestibule $3 \frac{1}{4}$ to 4 feet square be built in front of the doors. In case of a wooden silo, the framework of the chute is nailed directly to the silo; in case of masonry, bolts should be placed in the wall so that $2 x 4$ 's may be bolted to the wall, thus serving to connect the chute to the silo. The wood chute is more common than masonry, but masonry is sometimes desired on account of its fire-proof qualities, being more permanent and warmer than the ordinary wood chute. If a monolithic concrete chute is to be attached to a mono- 
Itnic concrete silo, the two should be built up at the same time and securely tied together. Some reinforcing should be used in such a chute.

If the chute is to be of clay blocks, it need not be built up at the same time as the silo, though it is usually found more convenient to do so. The chute must have a trap door or a dormer window in the roof extending out over the chute. At the bottom the chute should be connected to the feedway of the barn; sometimes, if considerable silage is fed outside the barn, it will be found advantageous to set the silo far enough from the barn so that a wagon can be driven under the chute between the barn and the silo, when large doors may be put in the bottom of the chute.

Points on Floors. In many localities a special silo floor is not considered essential or even advisable. Every one agrees that the floor may be more often dispensed with than the roof. The floor, however, is a considerable advantage. It helps prevent water from seeping into the silo, and reduces the difficulty of cleaning out the silo before refilling. Concrete is usually used for this, but it need not be made thick nor expensive. A three-inch floor is thick enough, but it should be made quite dense, generally 1 to 4 , unless the gravel is exceptionally good.

In some cases where gravel is expensive, paving blocks or even good hollow blocks may be used to advantage as flooring by simply plastering them with cement mortar. The floor should generally be slightly dished in the center, 6 to 10 inches being common. 


\section{CHAPTER VI \\ ERECTION OF STAVE SILOS}

ERECTING WITH SCAFFOLD

Inside and Outside Scaffolds. In the use of the scaffold two quite different methods have been followed. In one, the scaffold is built inside and in the other, outside of the silo. The former method is not common and is of questionable success, as an outside scaffold is most necessary for putting on the steel. The inside scaffold uses a little less lumber than the outside, but it is about as much trouble to build and does not have the advantage of being out where it is needed for conveniently putting on the steel or hoops.

Construction. As seen from Fig. 13, in building the outside scaffold, place $2 \times 6$ uprights a short distance from the foundation and about 8 or 9 feet apart. Thus the number of the uprights will depend upon the size of the silo that is being built. Usually the scaffold is built 16 feet high, thoroughly braced, and with brackets placed near the top of the uprights and extending in toward the silo. The uprights must be thoroughly braced, not only to one another, but to stakes in the ground, farther out from the foundation.

Before building the scaffold, the door frame should be upended in place and thoroughly plumbed and guyed in every direction.

If the silo is to be built in two sections with the lap only 2 feet, it is convenient to build the silo to the height of the scaffold before extending the scaffold any further. A few of the lower hoops can be then put in place and the silo made fairly stable before extending it any higher. If the staves 
are lapped more than 2 feet, or full-length staves are used, it will be necessary to build the scaffold full height before erecting any of the staves. The first thing to do is to erect the door frame.

The uprights are then spliced to the lower ones and the scaffold built another section higher in much the same manner as at first. In securing the staves in place, it is necessary to have common plastering lath, 3-inch bats, or salt or lime barrel staves which have been soaked over night in order to get them to bend easily. As the staves are put in place nail these strips of lumber to them to hold them together.

Handling the Staves. In any method of erecting it will be found most convenient to clamp three staves together before raising. A convenient method of doing this is to set saw horses upon reasonably level ground and match the silo staves together upon them. Then nail the convex or outside surface of the barrel staves fast to the inner surface of the silo staves, after the staves have been drawn reasonably close together. The barrel staves ought to be long enough to project 6 or 8 inches beyond the edges of the two outer staves so that as each section of these staves is upended, the projecting ends of the barrel staves may be nailed to the portion of the silo which is already erected. In this way crooked or warped staves do not give as much trouble as when set up singly; also clamping the staves together holds them better.

The difficulty of lifting a heavy section is overcome by the use of a rope and pulley. The pulley may be attached to one branch of a " $U$ " doubletree clevis, which is then hooked over the top of the last stave set up; by passing the rope through this pulley and taking a timber hitch around the three staves they can be easily raised by a man on the ground. The rope should of course be hitched a few feet from the end, 


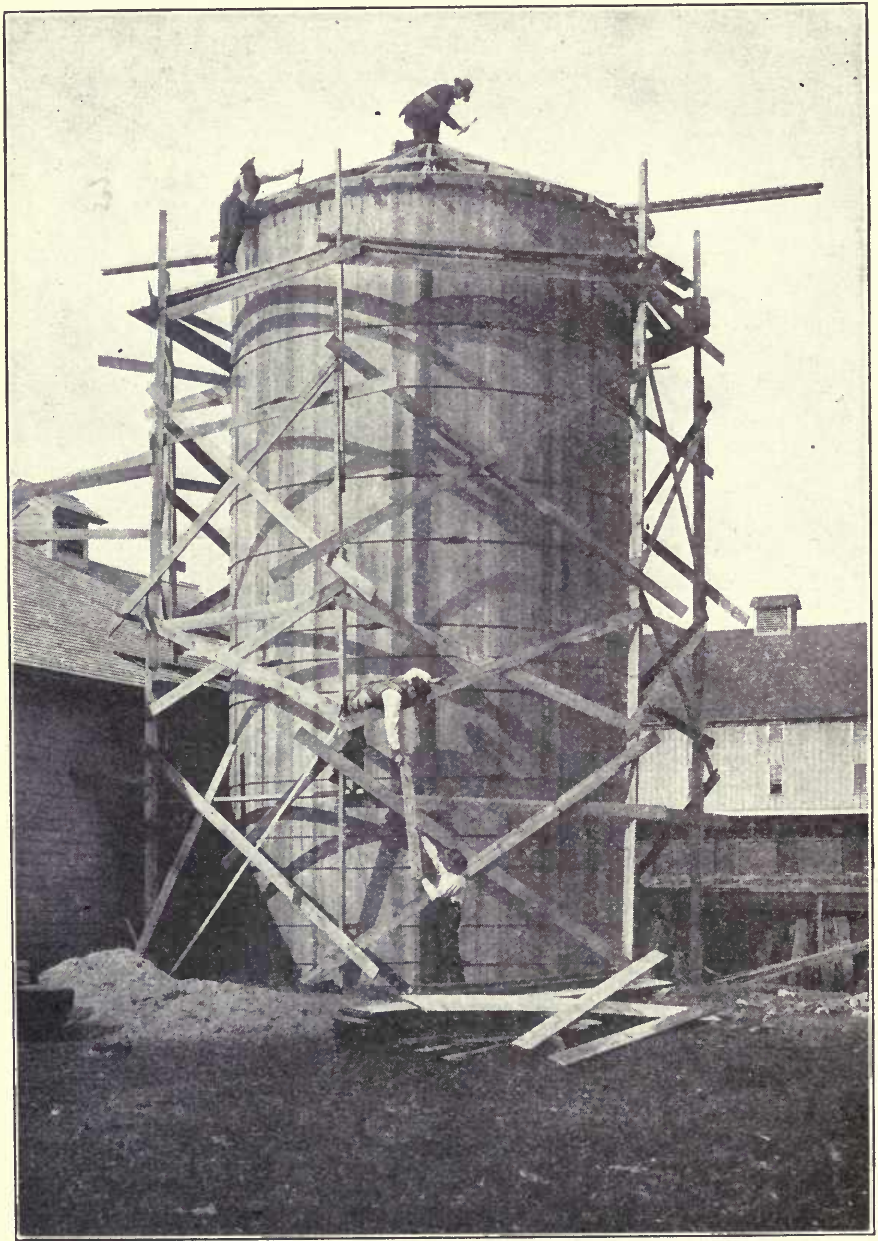

Fig. 13. Erecting with outside scaffold. 
but not so far that the man at the top will have difficulty in reaching down to unfasten it.

\section{ERECTING WITHOUT A SCAFFOLD}

While the most common practice is to use a scaffold, the author has had better success with no scaffold at all, and he very much prefers that method. This has been his experience with silos of various sizes.

The first step, as in the other methods, is to secure the door frame firmly in place. This makes it perfectly safe for one man who can work handily some distance from the ground, to go to the top of the door frame and manipulate the clevis and pulley, secure the top end of the sections when they are raised, and loosen the rope and pass it back down to the men below. As in the previous method, the staves are clamped together with three barrel staves if the silo staves are full length; if not, it will be necessary to use four barrel staves, one at the top, one at the bottom, and one at each joint. No scaffold is in the way to interfere with the raising of the sections. The clevis is simply hooked over the top of the door frame and a section drawn up.

After the bottom of the section is put in place it is a very simple matter for the man above to loosen the rope, draw the section over and place one end of the barrel stave to the door frame for nailing. Nails should be set in the end of the barrel staves before raising, as it is sometimes difficult for the man at the top to get more than one hand free at a time. If there happens to be much of a wind blowing it is well to nail a scrap of 1-inch lumber on the ends of the staves and the top of the door frame so as to hold the two together more securely. The 1-inch pieces should extend pretty well across the door frame so that two or more nails may be placed well apart, thus stiffening the entire part that is already up. 


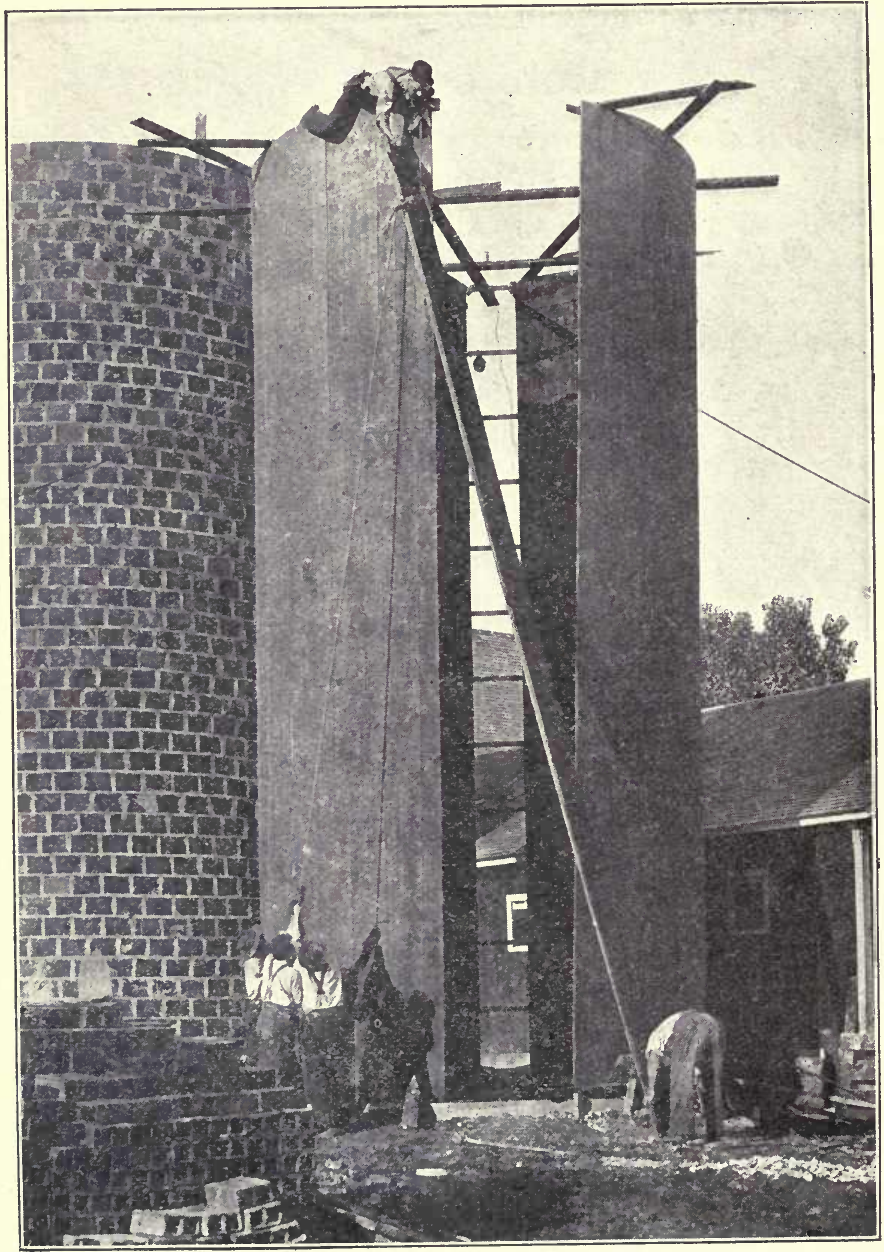

Fig. 14. Erecting the silo without a scaffold. 
The second section may next be raised and secured to place with the barrel staves. After this is done, ordinarily, it is best to take the pulley and clevis to the other side of the door frame and set up two sections there in exactly the same manner. Next, a $2 \times 6$ or $2 \times 8$ (nearest door in Fig. 15) is placed across the silo and nailed to the top of the last stave on each side. If the wind is blowing seriously it will be advisable to stretch No. 9 wires from the ends of these $2 \times 6$ 's out to stakes driven in the ground some distance away and approximately in line with the $2 \times 6$ 's. Now two more sections may be raised, and secured by means of one-inch scraps of lumber and nailed to the $2 \times 6$ in the same manner as the first section was secured to the door frame. These two sections should be placed on opposite sides of the door frame, and another piece of $2 \times 6$ lumber placed across the silo as before shown in Fig. 15.

Closing the Circle. It is usually rather difficult to decide just what size of circle to set the staves on. It is necessary to allow for the staves going together rather loosely, yet it is difficult to know just how much allowance to make. For this reason, when the silo is about half erected, some measurements should be taken to find out whether or not the staves remaining to be used will close the circle properly. If not, the staves must be set a little further out, or a little closer in, as the case may require. After the circle is closed by raising sections alternately on each side of the door frame, nail another scrap of lumber on top of the last staves erected, tying both sides securely together. This system of bracing is shown in Fig. 15. No. 9 guy wires should be used as needed, depending, of course, upon the weather.

Putting on the Hoops. The staves are now ready for the hoops. Put them on, commencing with the second from the bottom. A short piece of hoop is always provided to use 
with the first, in order that it will reach around the first time. All nuts are then turned up, drawing the silo together snugly. The first and third hoops can then be connected

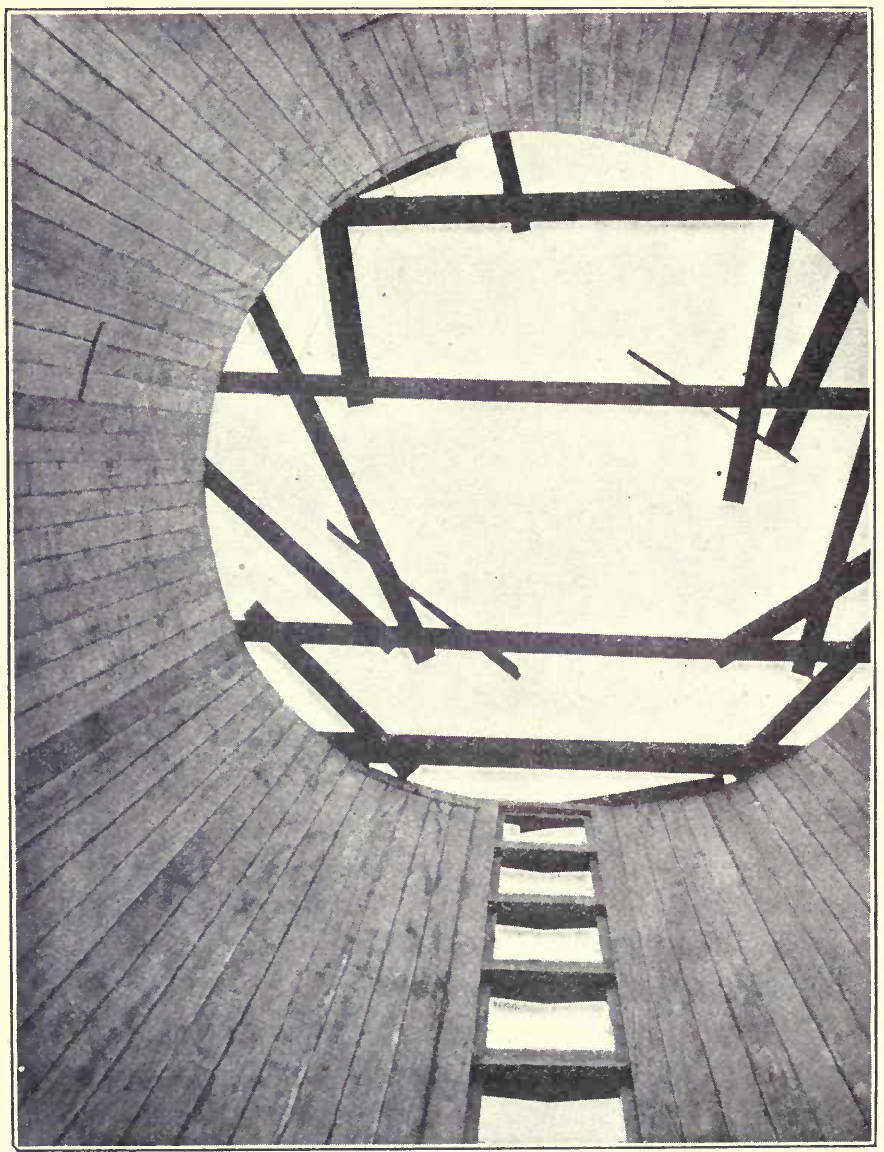

Fig. 15. Erecting the silo without a scaffold. 
without the use of the extra section. Put on each successive hoop up to as high as can be reached from ladders resting on the ground, being sure to mark the spacing of the hoops carefully.

If a scaffold is used it is a comparatively simple matter to stand on the scaffold and put on the successive hoops, tightening them enough to hold the silo firmly in place.

If a scaffold is not used, the steel may be put on in the following manner: Drive two spikes into the silo in such a manner that the hoops, which should first be properly bent to fit the silo, may rest upon these nails. The nails should be placed about $1 / 4$ the length of the hoop from each end of it. Then place a ladder convenient to each nail and let a man on each ladder carry one end of the hoop section and place it on the nails. The entire hoop is put in place in this way, and then each man may go to a joint and put on the lugs and bars. In this way the lower half of the steel can be placed upon a 30 - or 32 -foot silo. It is then a simple matter to hook the ladders to the top of the silo and finish putting on the steel. The permanent guy wires should be placed and the silo plumbed before thoroughly tightening the hoops or putting on the roof. It must of course be borne in mind that the lugs must not all be placed on one stave; they must be "staggered" around the silo. 


\section{CHAPTER VII \\ MONOLITHIC CONCRETE SILOS}

In the building of silos in which the concrete walls are moulded or as we generally say, monolithic silos, the common thickness of wall is 6 inches. This is plenty heavy enough for any reasonable size, up to a diameter of 25 feet and a height of 50 to 60 feet. The mixtures used will of course depend very largely upon the grade of gravel or other aggregate. Mixtures of 1 to 4 and 1 to.31/2 are, however, usually found in the best silos. Stones should never be found in the wall larger than one-third the thickness of the wall.

Reinforcement. Vertical reinforcement is commonly recommended for concrete silos, but it is of little or no importance, as there has never been a failure due to lack of vertical reinforcement in any masonry silo, except where a very thin wall has - en built or the horizontal steel placed over 3 feet apart.

The horizontal reinforcements may be determined from the table on page 78. If other sizes of steel are used than those shown in the table it will be a simple matter to determine the equivalent amounts. One $3 / 8$-inch rod is equal to two $1 / 4$-inch rods, while one $1 / 2$-inch rod is equal to four $1 / 4$ inch rods.

Forms. In the building of a concrete silo a scaffold may be arranged similar to that described in the building of block silos, but in addition to this equipment, forms will be necessary. Several kinds are on the market at present, and usually reliable information may be secured concerning them. The author has not had wide enough experience in their 


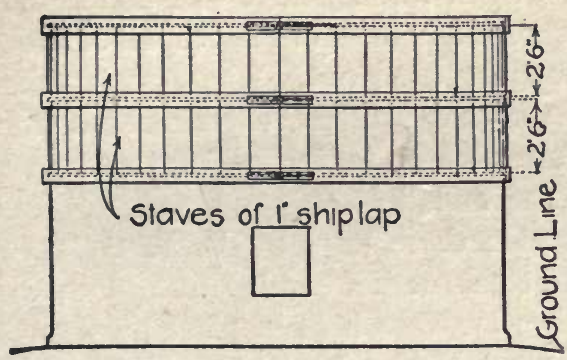

COMPLETE FORMS IN PLACE
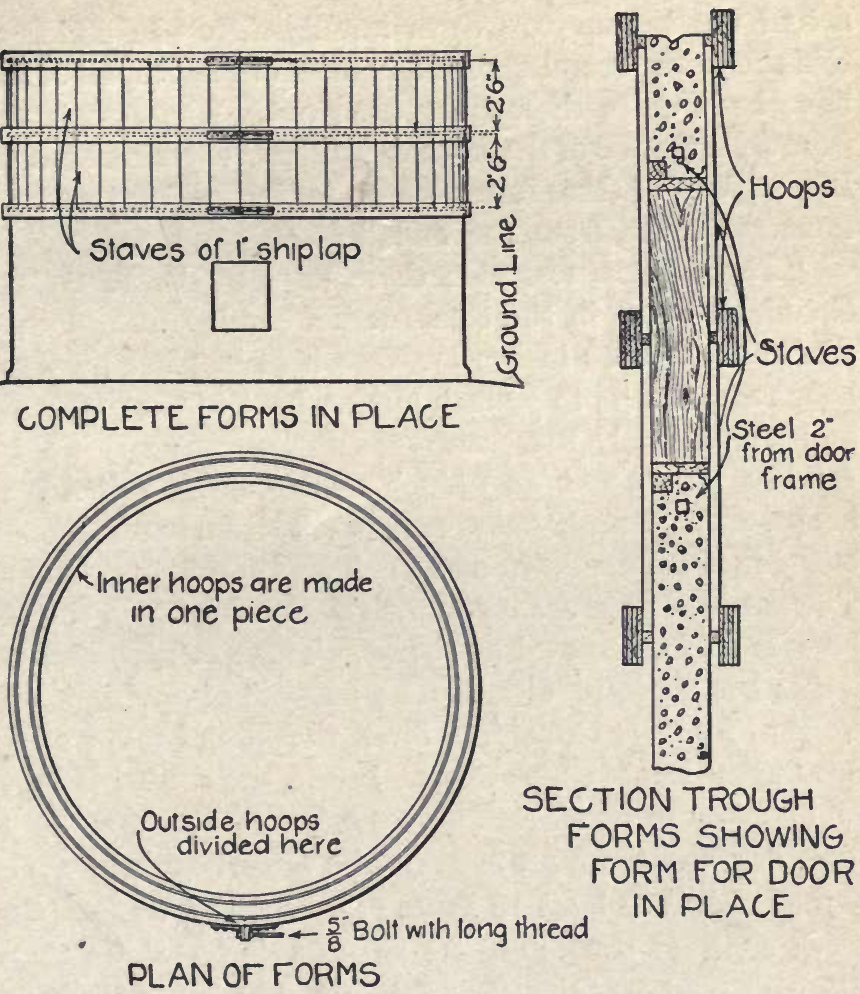

SECTION TROUGH FORMS SHOWING FORM FOR DOOR IN PLACE

PLAN OF FORMS

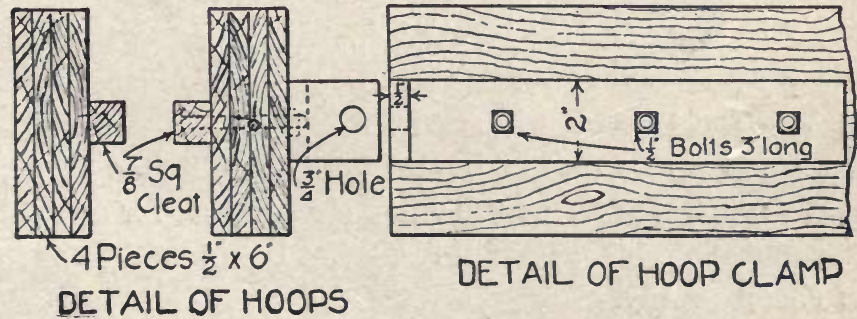

Fig. 16. Wooden forms for concrete silos. 
actual use to compare them intelligently. In addition to this there are several types of homemade forms, all of which have been quite thoroughly tried out. The first is taken from Bulletin 100 of the Iowa agricultural experiment station. Illustrations of these forms are shown in Fig. 16; the descriptions are taken from the bulletin.

"These forms resemble those used by R. L. Sollet, of Goldfield, Iowa, in the construction of his silos. Two sections of staves 30 inches long are held in place by wooden hoops made of $3 / 8$ to $1 / 2$-inch lumber bent to the proper circle and nailed firmly together.

"The staves rest on $7 / 8$-inch square cleats nailed to the hoops. The inner hoops are made solid; and to remove them, one side is driven down and the hoops sprung out of round. The outside hoops are made with clamps by which they may be opened for removal as shown. Three outside and three inside hoops are required. The purpose of having two sections of forms is twofold. First, the second set of forms is accurately located by the first before the second is moved, and also by using 30 -inch staves 5 feet of wall may be built each day and the form need not be disturbed until the contained wall is at least 18 hours old. Second, no tamping of fresh concrete occurs on the unsupported wall, as there is always a section of the forms below the one being filled. The 30 -inch stave length was chosen because longer staves are likely to bend, and the length is handy for fitting the doors, which are 30 inches high inside and placed 30 inches apart."

The same staves will serve for any diameter of silo and the hoops can be made adjustable within a limited range, so that a few sets of hoops will equip a contractor for any diameter of silo. This system of forms has been found to be fully as cheap as any. 
With this type it is convenient to use scaffolding of the same plan as shown in the article on clay block silo construction. There are several patented systems embodying scaffold and forms. They are quite generally advertised and may be learned of in that way. There are several systems not patented.

In some cases it will be found convenient to use thin sheet metal for outer forms, but the inner forms must be either of wood or quite heavy steel on account of the danger of collapsing. If, however, a rigid inner form is used, the outer may be of light material and may be spaced accurately from the inner form. This secures a properly shaped wall of uniform thickness. Any forms should be cleaned every time they are used, and usually it is well to coat them with grease or oil. This, however, leaves some grease upon the surface of the concrete and interferes with plastering in case it is desired.

It is ordinarily advantageous to use two forms, the second being put in place and filled before the first is removed. With any system there should be separate forms for the door frame, that is, it should never be necessary to use a wooden frame in a concrete silo. After setting the forms they should be filled around evenly about six inches at a time. Concrete should not be dropped a great distance into them or any other rough handling done with them, as it is not advisable to go to the trouble of making forms that will stand much abuse. The concrete should be thoroughly tamped or rammed with a light rammer, and there should be sufficient water in the concrete to work to the surface by this process. The concrete should be thoroughly spaded near the walls, in order to give it a smooth and even surface.

In putting steel into the concrete, place it at a reasonably uniform distance apart and about half way between the inner 
and the outer forms, but in no case put any reinforcing material closer than 1 inch from the surface of the concrete, also avoid any reverse curves in the steel. Where two pieces of reinforcing steel join they should lap at least 2 feet, to prevent slipping. Usually, good concrete need only to set over night, when the form may be removed and raised.

One advantage of using two sets of forms is that in no case is it necessary to remove them until 18 hours after they have been filled. The common depth of a set of forms is $21 / 2$ to $31 / 2$ feet, but by using two sets, 5 or 6 feet can be added to the silo each day.

Vertical reinforcement should be used on each side of the doorway. In any silo more steel should extend across the doorways than is found in other parts of the wall. Wall reinforcement ending at the doorway should be hooked to the vertical reinforcement.

Plastering. In case it is necessary to plaster this silo it is most conveniently accomplished on the outside from a swinging scaffold either suspended from the forms, or, if the silo is completed, the scaffold may be supported from the cornice. On the inside, it is usually most convenient to remove the forms and plaster from the scaffold as it is lowered. It is better, however, to plaster the silo if possible before it has thoroughly dried, as there is not much danger then of the plaster drying too rapidly.

Methods of hoisting material will vary with different systems of forms, etc. In most outfits on the market a convenient method of hoisting is provided. If, however, other means are not available, a gin-pole, shown in connection with block silos, Fig 22, will be found very convenient and strong enough to hoist at least 100-pound loads. 


\section{CHAPTER VIII}

\section{THE IOWA SYSTEM OF BUILDING BLOCK SILOS}

Construction of the Wall. The first course of blocks in an Iowa silo should be a trial course, the blocks spaced 1/8 to $3 / 16$ of an inch apart, without mortar, in order to determine the proper diameter of the silo and the length of the guide. This will overcome the necessity of cutting blocks. Steel should be placed upon the outer half of the mortar course, in order that there shall be enough mortar inside to bear against the wire and hold the blocks. In case of a double wall the steel should, of course, be on the inner wall.

Loose blocks may be placed temporarily upon the wall to hold the steel in place at intervals of 6 or 8 feet, as occasion requires. Steel reinforcement in the joints below and above the doorways should be long enough to lap past each other and be hooked, as shown in Fig. 19.

The horizontal or bed joints should be thoroughly bedded to cover the steel reinforcement. The vertical joints at the block end should be made with care in order to insure perfectly air- and water-tight joints. In order to do this the ends of both blocks should be mortared before pressing together. The outside joints should, for the sake of appearance, be struck neatly with the trowel as the work progresses, and for warmth they should of course be air tight. On the inside, however, this is scarcely sufficient, as there might still be an occasional opening left between the ends of the blocks, which would permit the air to enter.

The Cement Wash. In order to close all such openings, leave the mortar hanging on the inside or cut it roughly; then, 
while still green, wash with a cement wash before the scaffold is raised or the work left for the night. This wash naturally brings to view any crevices which may exist. These may be then filled with mortar and thoroughly sealed on the inside of the wall. This wash is composed of cement and water

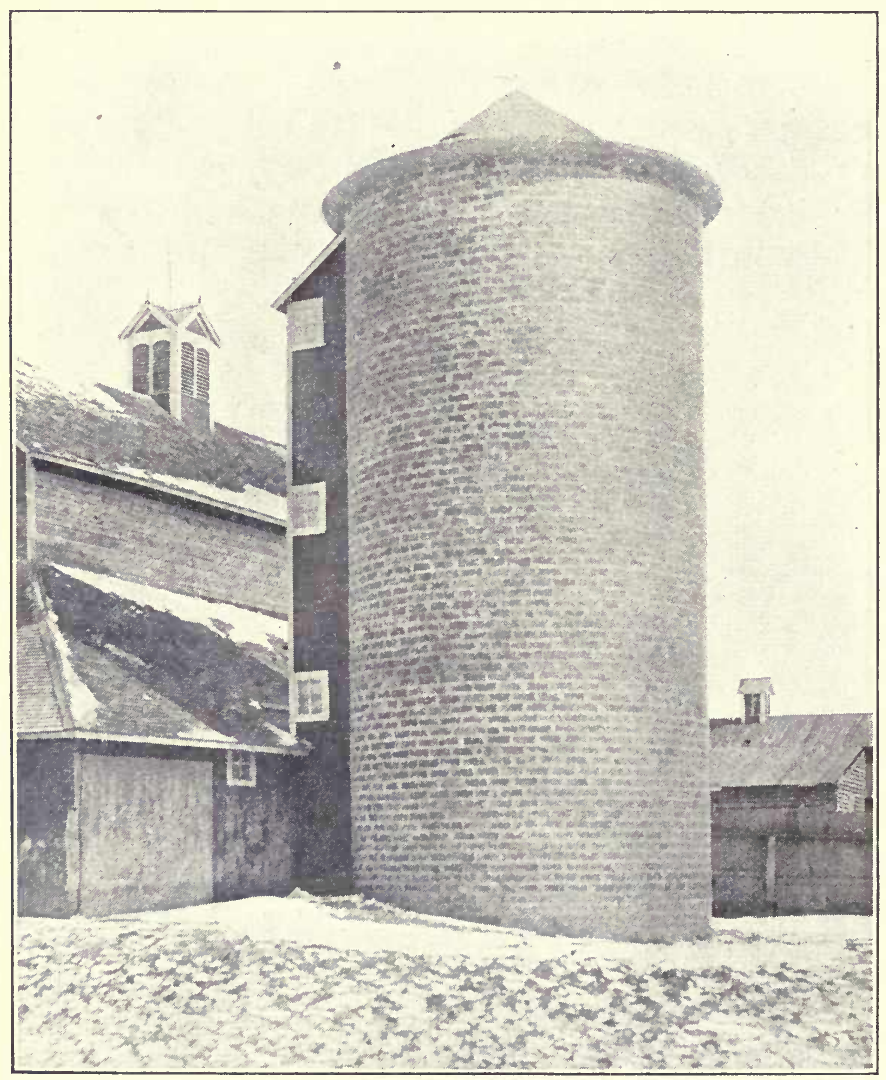

Fig. 17. The clay block silo. 
mixed to about the consistency of good paint, and can be applied with a broom. The wash should be applied vigorously, in order to smooth down and fill the irregularities.

Scaffolding. It is difficult to overestimate the advantage of convenient, safe, and simple scaffold for any masonry construction. Three distinct types have been tried by the author, and the one which is shown here was found to be superior to any other type tried. This and various modifications of it are in common use. This scaffold is shown in the drawing; all parts are lettered for the sake of a clear description. The top side of the scaffold is shown in Fig. 20.

This scaffold differs from most building scaffolds in that the platform is movable. The platform itself consists essentially of a square framework of $2 \times 8$ 's or $2 \times 6$ 's for a small silo, of a rea-

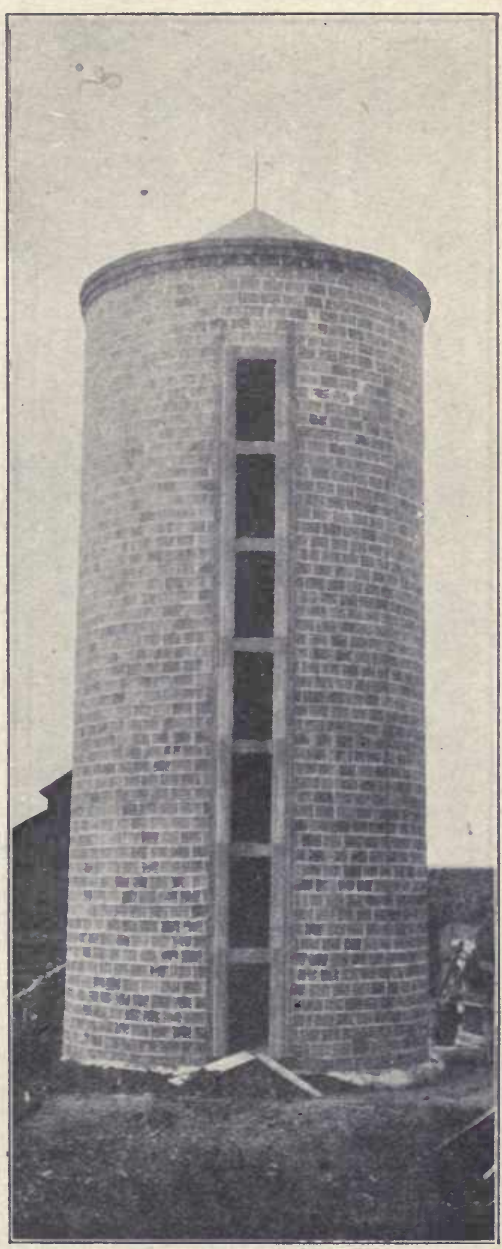

Fig. 18. The clay block silo. 


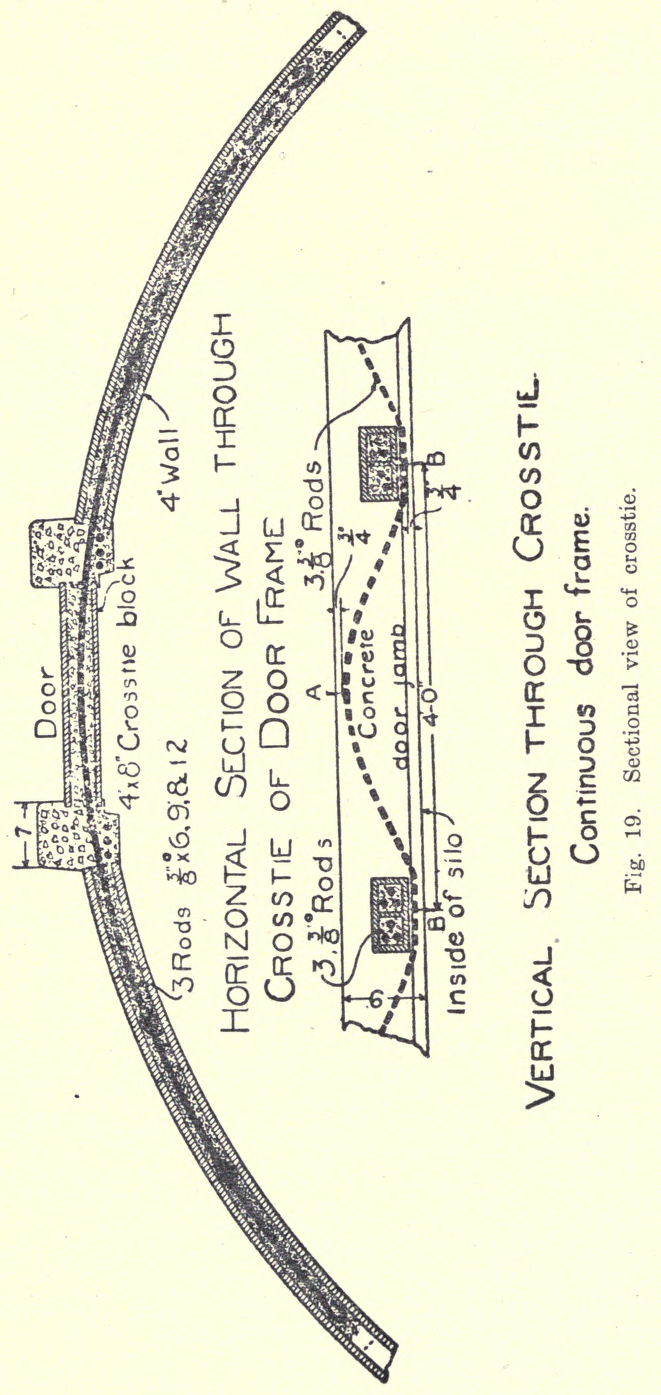


sonably clear, stiff lumber. These are shown by the dotted line $A$. At the ends of these and flush with the bottom of each are securely nailed 2 -inch pieces, $B$, of convenient length. Thus the bevel at the end extends through three 2 -inch pieces instead of one, and furnishes ample bearing upon the supporting pins, $N$. Instead of resting upon pins, the scaffold is sometimes hung by means of clevises and short chains. There should be at least $1 / 4$ inch of clearance all around the post, $M$. This framework is held together at the corners by an eye bolt passing through a $2 \times 6$, four feet long, approximately ( $L$ shown beneath at the right-hand corner) and by the outer planks above. The eye bolts should be made of $5 / 8$ inch metal with a washer at each end. The diameter of the eye should be 1 inch inside. Four are required. A $2 \times 8$ or $2 \times 6, F$, is bolted at each end to blocks which in turn are nailed to the middle of the two opposite members, $A$. Upon this framework is placed a $2 \times 10$, indicated by $G$, lying flat across the center of $F$ and the two members, $A$. - Extending at right angles from $G$ and lengthwise but not central upon $F$ are two $2 \times 10$ 's, indicated by $H$. A block is nailed under the longer $2 \times 10$ not supported by $F$, and nailed to the inner end of these timbers, $H$, are blocks which extend two inches under $G$. By placing these blocks on each side of $F$, it is not necessary to nail $H$ to $F$. It is highly desirable in a scaffold which must be used repeatedly that no nails should be drawn when taking it apart. Upon the corners of and diagonally to this frame are laid, inside of $D$, two widths of $2 \times 12$ planks, lettered $I$; and connecting the ends of these and resting upon the ends of $G$ and $H$ are three $1 \times 12$ boards, five feet long, lettered $J$, beveled at the corners to fit the circle; also five $1 \times 12$ boards, lettered $K$, which are not beveled. The four $1 \times 12$ boards, lettered $R$, complete the upper part of the platform. 
If strong 1-inch hardwood lumber is at hand, it may be substituted for the 2-inch upper foot planks shown in the drawing. In fact, this plan may often be changed to suit the materials at hand, but in case all new materials are to be bought, the plan shown will be found to give general satis-

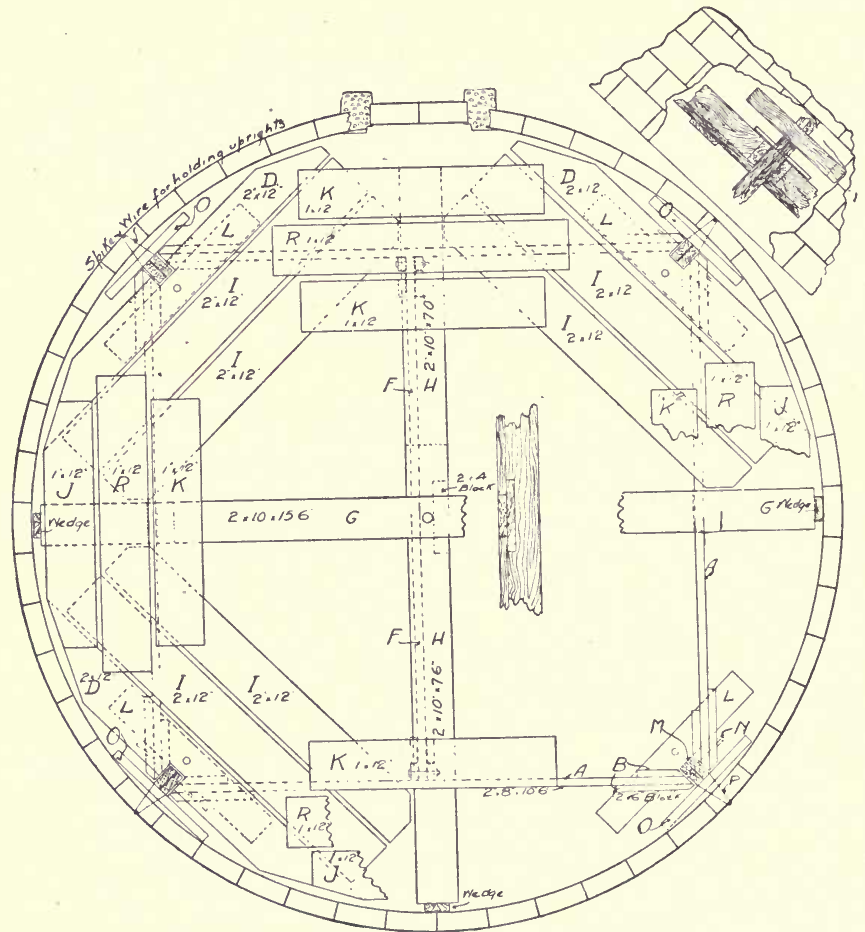

Fig. 20. A scaffold for the Iowa silo.

faction since all parts, having been used repeatedly, are known to be sufficiently strong. Four upright posts, $M$, secured to the wall at points approximately equally spaced, support the scaffold platform by means of $3 / 4$-inch round 
steel pins 16 inches long, $N$, extending through 1-inch holes in the uprights. Eight of these are required, as one set should not be removed from a lower hole until the other pins are placed to support the scaffold in case any of the hoisting parts should break. As already noted clevices and short chains may be used to suspend the scaffold instead of supporting it from below.

Each upright consists at first of a $2 \times 6$ eight feet long and a $2 \times 6$ sixteen feet long screwed together with three $21 / 2^{-i n c h}$ No. 14 or No. 16 flat-headed screws. It is necessary to use flatheaded screws in order that the head will countersink itself into the wood, thus not interfering with the raising of the scaffold platform. One of the bottom members of the upright is 8 feet long and the other 16 feet long in order that the post may be added to as needed by simply screwing 16 -foot $2 \times 6$ 's on alternate sides. These upright posts are secured to the wall by means of light wires, $P$, which are placed about 3 feet apart vertically. Every alternate time the scaffold is moved, 2 -inch blocks, $O$, should be placed snugly between the post and the wall and nailed to the wall. This places the post about three inches from the wall. Then it should be toenailed to the block, and the wires passing through the wall drawn tight. This holds the scaffold support rigid in all directions and enables the builder to keep them plumb. The distance between the holes in the upright will depend upon the kind of hoisting apparatus used, but usually 18 inches is most convenient. The most convenient device for raising the scaffold are 1/2-inch triple blocks.

\section{METHOD OF BUILDING}

The Guide Device. It is essentially important, for the sake of appearance, preservation of silage, and strength of wall that the silo be circular and plumb. It is highly desir- 
able that the guide be simple, easily used, and in the way as little as possible when not in use. A common board about 6 feet long and cut to proper curvature also aids in getting a good, smooth, round wall. It is of course possible to build a circular wall by starting the circle, then using the plumb at intervals on the wall. However, the guide devised has been

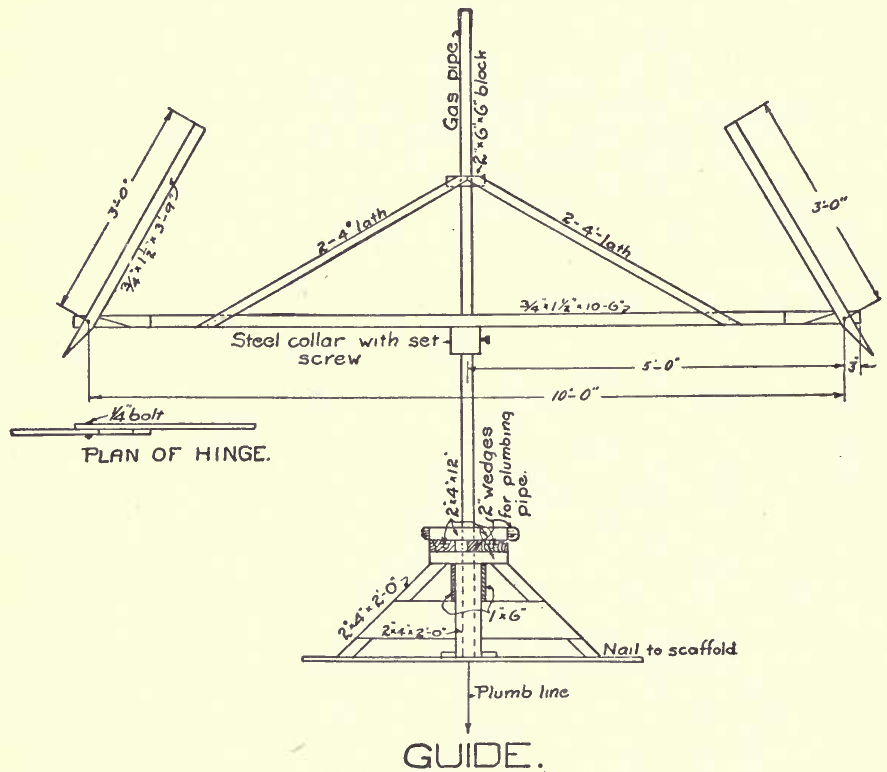

For laying wall plumb and to true circle.

Fig. 21. A guide device used in constructing the wall.

found better for this purpose by men who have tried both ways. It is also advantageous, since, by means of it, the owner of the silo may in a very few minutes detect any faulty shape of wall. It is merely necessary to determine the proper position of the center-pipe by means of the plumb-bob; 
then follow the end of the guide around the wall. All blocks should be within less than $1 / 2$ or $3 / 4$ inch of the guide, and even these variations should be gradual so as not to form shoulders in the wall.

The device is shown in Fig. 21. A piece of 1-inch, or larger, straight gas pipe, indicated by $A, 7$ or 8 feet long may be secured as a center about which to revolve a light arm, $B$. The outer extremities of this arm, $X$, are hinged, in order that it may not interfere with walking around the scaffold. Also, when not in use, $C$ may be placed in the position shown in the figure. It is not necessary to use the guide for each block, but it is convenient for determining whether or not the blocks are properly placed by means of this guide, before the mortar joints are pointed.

The stand, $D$, is made of $2 \times 4$ 's or any convenient lumber by means of which the gas pipe may be held in a vertical position in the center of the scaffold. The collar and set screw, $E$, are used to raise the revolving arm to a level with the top of the course being laid. The upright, $F$, and two laths, $G$, serve the purpose of holding $B$ in a horizontal position.

It will be readily seen that this guide at once becomes useful not only in securing a circular wall but in making the course level, as the end of the arm, of course, revolves in a horizontal plane. This device has proven itself to be very convenient. In order that the pipe $A$ may be in the center of the silo after each raising of the scaffold, it is only necessary to pass a plumb line from the center of the pipe through the board supporting the pipe to a nail in a stake in the bottom of the silo. With this as an indication of the proper location of the guide stand, the latter may be moved to place and nailed lightly. After raising the scaffold, the first thing to do, of course, is to drop wedges between scaffold and wall or 
secure a scrap of lumber to the scaffold by one nail so the end, in turning about the nail, will strike the wall.

Hoisting. Two general methods have been followed in hoisting materials to the scaffold. In one method a pulley is secured to the outer end of a $2 \times 6$ projecting over the wall and the material is hoisted by a horse. This method is found to interfere with the use of the guide of Fig. 22; therefore a derrick after the plan of Fig. 22 has been devised.

This derrick, 48 feet high, is built of three $2 \times 6$ 's 16 feet long, $A$, and six $1 \times 6$ 's 16 feet long, $B$, besides the pieces necessary for the arm at the top. As seen in the cross-sectional view in the center, the $1 \times 6$ 's are nailed flatwise upon the edges of the $2 \times 6$ 's, thus forming an I beam. All of the members are so placed that no joints are closer than 5 feet 4 inches. Two short 1x 6 struts, $E$, supports each end of the $1 \times 6$ pieces, $C$. Two No. 9 guy wires, $F$, are secured to the end of $C$ toward the silo and fastened to stakes driven into the ground a considerable distance away from the bottom of the derrick. These prevent any side motion of the arm where the pulley is attached, while a third guy wire is fastened to the other end of $C$ and secures the derrick in the other direction. This derrick has been thoroughly tried out with loads up to 400 pounds. With the usual loads of less than 100 pounds it is entirely safe. The derrick itself is most easily raised by being constructed on the ground and raised after the guy wires, pulley and rope have been attached.

\section{DOOR FRAMES}

Reinforcement. The door frames are reinforced both vertically and horizontally with steel having a cross-sectional area equivalent to $1 / 4$ square inch, or a square reinforcing bar $1 / 2$ inch by $1 / 2$ inch. 

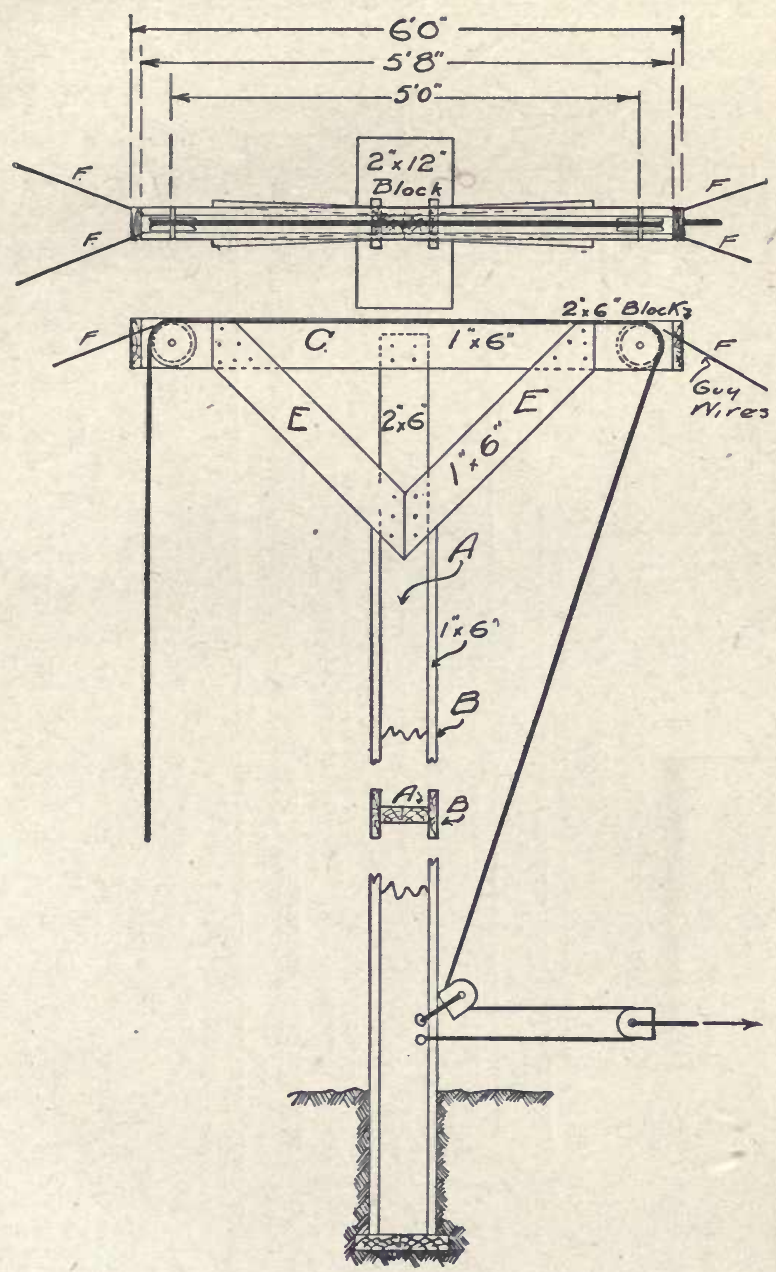

Fig. 22. An efficient derrick. 
The vertical reinforcing is bent as shown in Fig. 19, and

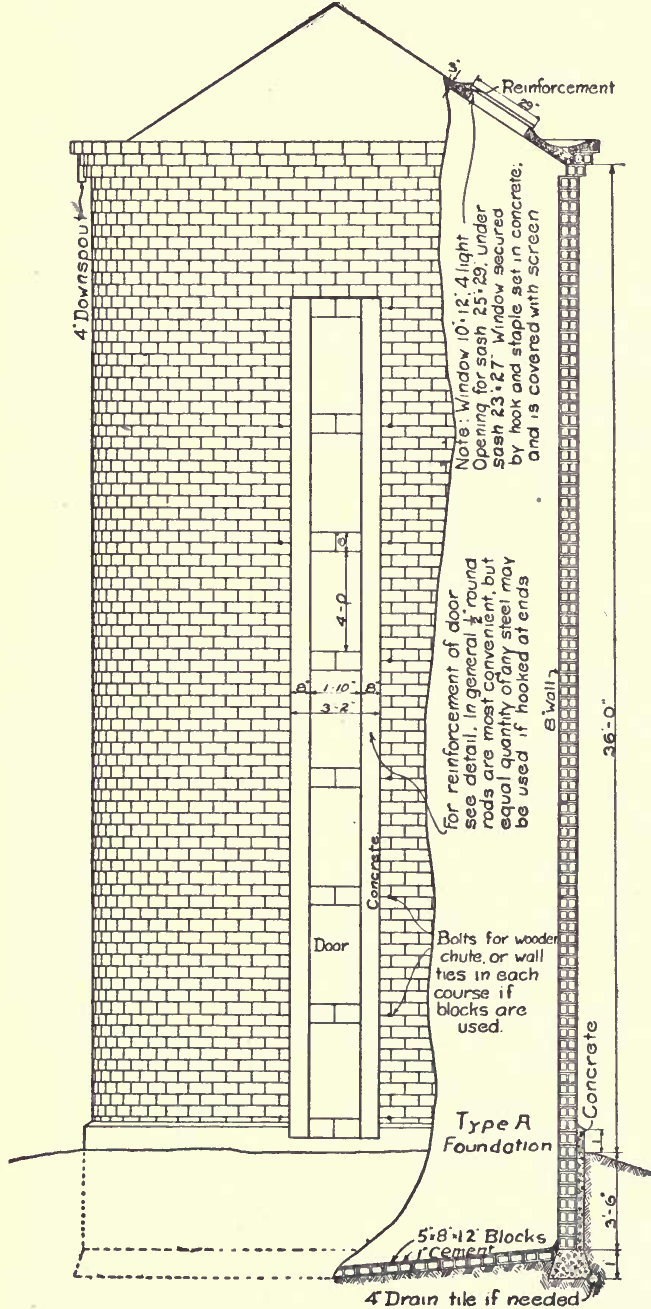

Fig. 23. Elevation of the doorway. wired in place, while crosstie steel is placed in the wall. The steel used for crosstie reinforcing is cut in lengths of 7 and 11 feet and one of each length is placed in each half of the crosstie extending, theninto the wall on each side, except when cement blocks are used. The No, 3 wire used for horizontal reinforcement of the wall is hooked around the vertical reinforcement of the door frame.

The continuous doorway, shown in Fig. 23, consists essentially of a continuous door jamb 
on each side of the opening. These jambs are made of reinforced concrete and may be used with either clay or cement blocks. The horizontal reinforcements of the wall hook into the vertical reinforcements of the jamb. The jambs are tied together at intervals of 4 or 5 feet by steel within the crosstie block. This steel not only extends into the vertical jamb, but, in order to be more secure, extends several feet into the wall on either side of the jamb. As shown in Fig. 19, these crossties may be of steel and protected from rust by being incased within the clay blocks filled with concrete or within the concrete alone. When the wall has been completed to the height at which it is desired to commence the door, two blocks are laid upon the wall across the doorway. These should be placed out far enough so that the door may be set down inside without touching the cross blocks. The shoulder or ledge thus formed should be $13 / 4$ inches wide. Through this crosstie, and extending into the hollow spaces in the blocks on either side of the doorway, should extend the reinforcing steel, unless cement blocks are used, in which case this is not practicable, and the reinforcing steel may simply be hooked into vertical steel.

Upon this bottom crosstie must be placed the outer half of the continuous door form. Then the vertical reinforcement may be hooked to the lower crosstie and secured in a vertical position by tieing it to the form. Then the horizontal reinforcement of the wall may be hooked to or placed inside of the vertical reinforcement. When the wall is completed to the top of this form, the inner portion of the form may be bolted to the outer. The form, crosstie, and the wall into which the steel projects should be then filled with moderately wet concrete made up of reasonably fine gravel. The second form may be secured to the first by means of $2 \times 6$ 's. The use of the second form is similar to the first. It will thus be seen 


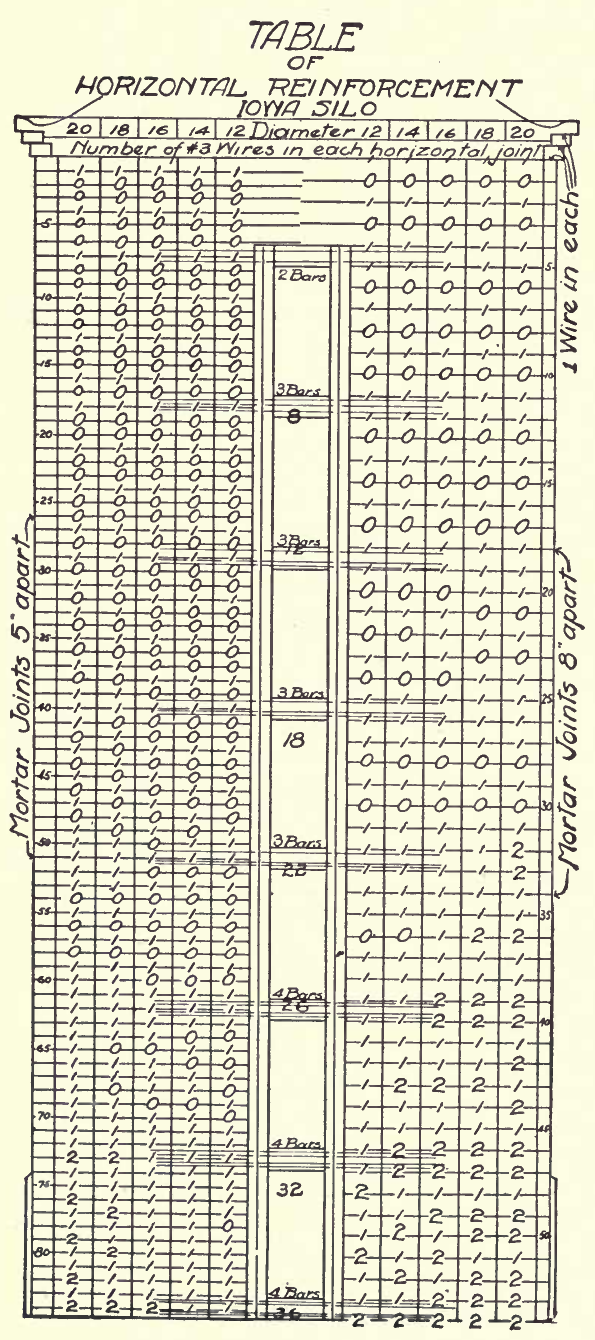

Fig. 24. Reinforcing plate. that the door frame consists of interlocking steel, thoroughly set in cement, which locks it, protects it from rust, and secures it in an air-tight manner to the hollow blocks of the wall by running into them a short distance.

Construction of the Door Forms. A detailed drawing of these forms, two of which are required, is shown in Fig. 26. The upper left-hand view shows the elevation; the upper right-hand view shows the form as seen from the side, while the lower plan view presents the form as seen from above.

One method of procedure in the construction of a 

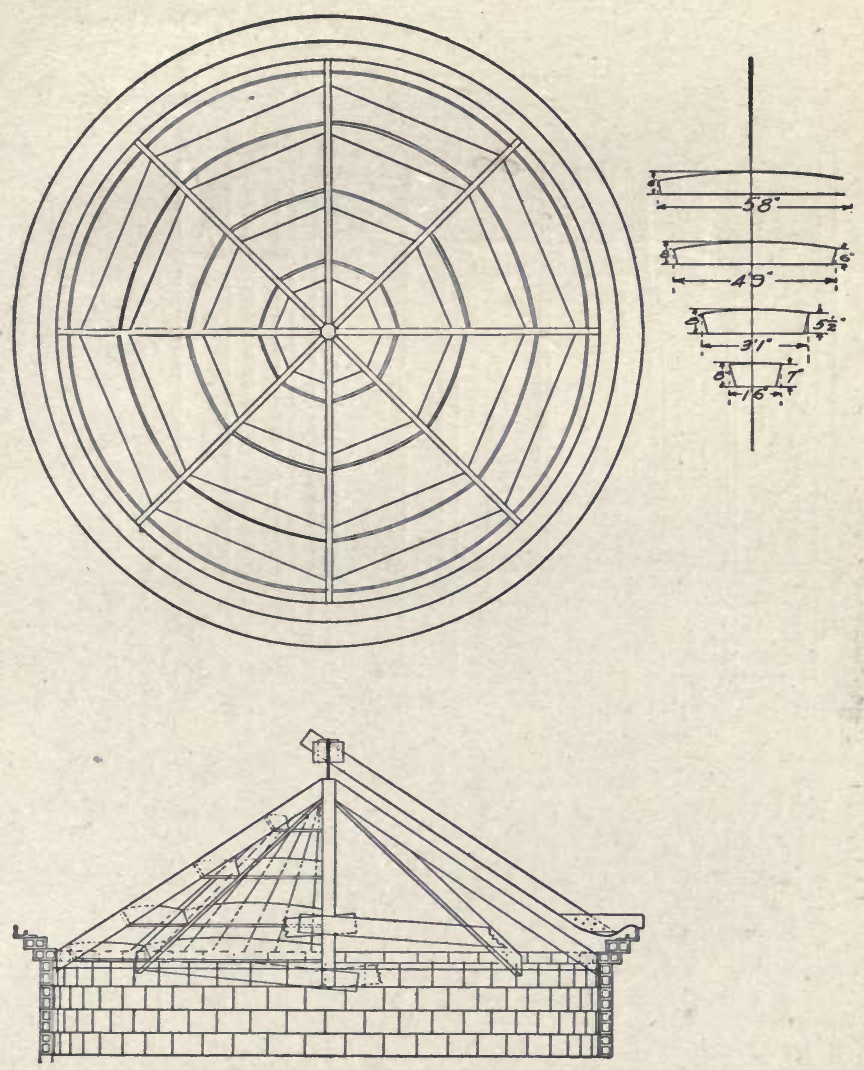

Fig. 25. Concrete roof construction.

set of these forms is as follows, each part being designated by letters and dimensions shown in the drawing. All surfaces coming in contact with cement should be dressed. First, two members, $A$, may be cut and pieces, lettered $C$, may be made from a 2x6. The edge nailed to $B$ should be beveled so that the piece will be flared in order that it may be easily re- 


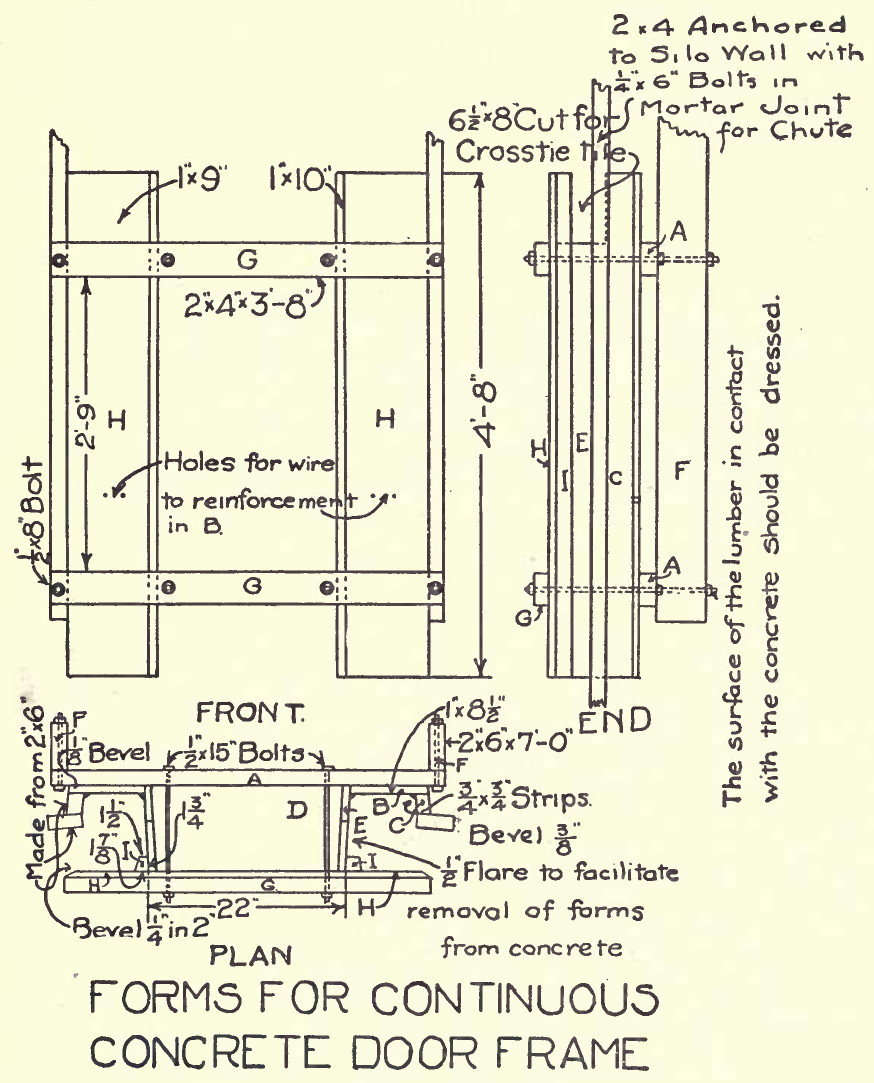

Fig. 26. Door forms

moved from the concrete. The outer edge of this member should be beveled about $3 / 8$ inch in order to have it fit the circular wall against which it must be clamped.

Two pieces, $D$, are required, and are cut from a 1 -inch board. The corner of the piece where $A$ and $E$ join should be less than right angles, in order that each of the boards, $E$, may 
slant $1 / 2$ inch toward each other. This is also for convenience in removing the form from the concrete. The member $E$ should be nailed back to $D$, as seen in Fig. 26. In

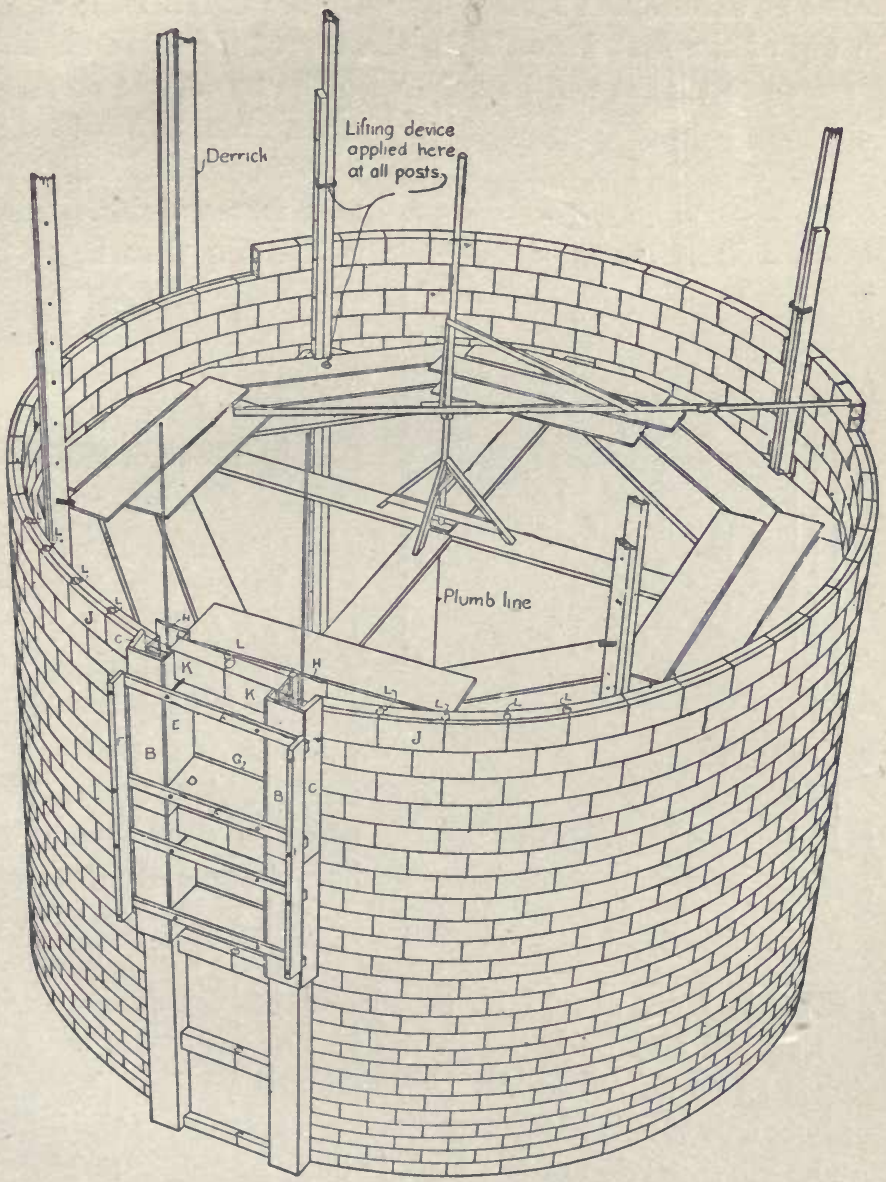

Fig. 27. Perspective view of Iowa Silo. 
order that the crosstie blocks may be set into each side of the form, it is necessary to saw a notch in $E$.

The length of these forms and the location of the notch cannot be determined accurately until the wall is built up to the top of the first form. Then the top of the form should be sawed so that it will be flush with the top of the crosstie

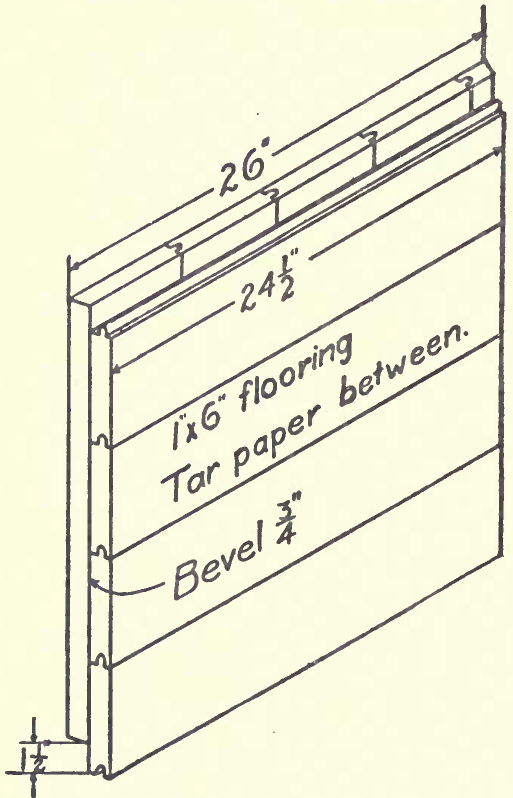

Fig. 28. Wooden door for continuous doorway. when the top of the crosstie is level with the wall mortar joint. The notch will then be of a depth equal to the width of the block and wide enough to permit the crosstie block to rest loosely between the outer and the inner form. The necessity of this will be readily seen in Fig. 27. The inside corners formed by $B, C$, and $E$ should be filled with a three-cornered strip, which causes the concrete door frame to be chamfered, leaving smooth work.

In the $2 \times 6$ 's, lettered $F$, Fig. 26, holes should be bored and $1 / 2$-inch bolts used. Holes should also be bored in the end of members $A$ and notches made as indicated. Holes should also be bored in $A$ for a long bolt to extend through the inner portions of the form.

The inner portion of the form is built as follows: Members, lettered $G$, are cut, and to them are nailed 10-inch 
boards, $H$, which are placed 22 inches apart. The boards, $H$, should be beveled on the edge $1 / 4$ inch in two inches, to conform to the curvature of the inner side of the silo wall. The edges need not be beveled thinner than $1 / 2$ inch. The beveled strips, $I$, are nailed to the end flush with the inner edge of $H$. Only a bevel of $3 / 8$ inch is necessary here, as the lumber of the door extends horizontally, therefore there is little or no shrinking or swelling of the lumber in this direction. Holes must be bored in $G$ to receive the bolts which hold the two parts of the form together. The cost of these forms need not exceed $\$ 12$. 


\section{CHAPTER IX \\ SAFE STRENGTH OF MATERIALS}

The Factor of Safety. In the use of any material it is of course important to know how much force or pressure it will resist. In testing materials the actual weight necessary to strain, bend, break, or crush them is accurately determined. It is evident that the largest load which a given material will carry cannot safely be placed upon it. The fractional part of the greatest strength which it is considered advisable to use, determines what is generally spoken of as the "factor of safety." For instance, a steel rod one inch square, which of course has a cross-sectional area of one square inch, would probably support, without breaking, any load up to 60,000 pounds, providing the load was suspended directly by it. But in case of silo building there should not be a force of more than 15,000 pounds placed upon it. This is called the safe strength of this material for this purpose, and is approximately $1 / 4$ of the ultimate or greatest strength. It is generally spoken of as the use of a factor of safety of 4 . If human life were more continuously depending upon this material, as is the case in residences, office buildings, or theatres, the factor of safety used would probably be 5 or 6 . Thus the safe strength of this material would then be 10,000 to 12,000 pounds per square inch. In masonry materials for silos the factor taken is not less than 8 .

Just what portion of its ultimate strength can be safely utilized, depends considerably upon the material and the seriousness of results in case a failure should occur. As already 


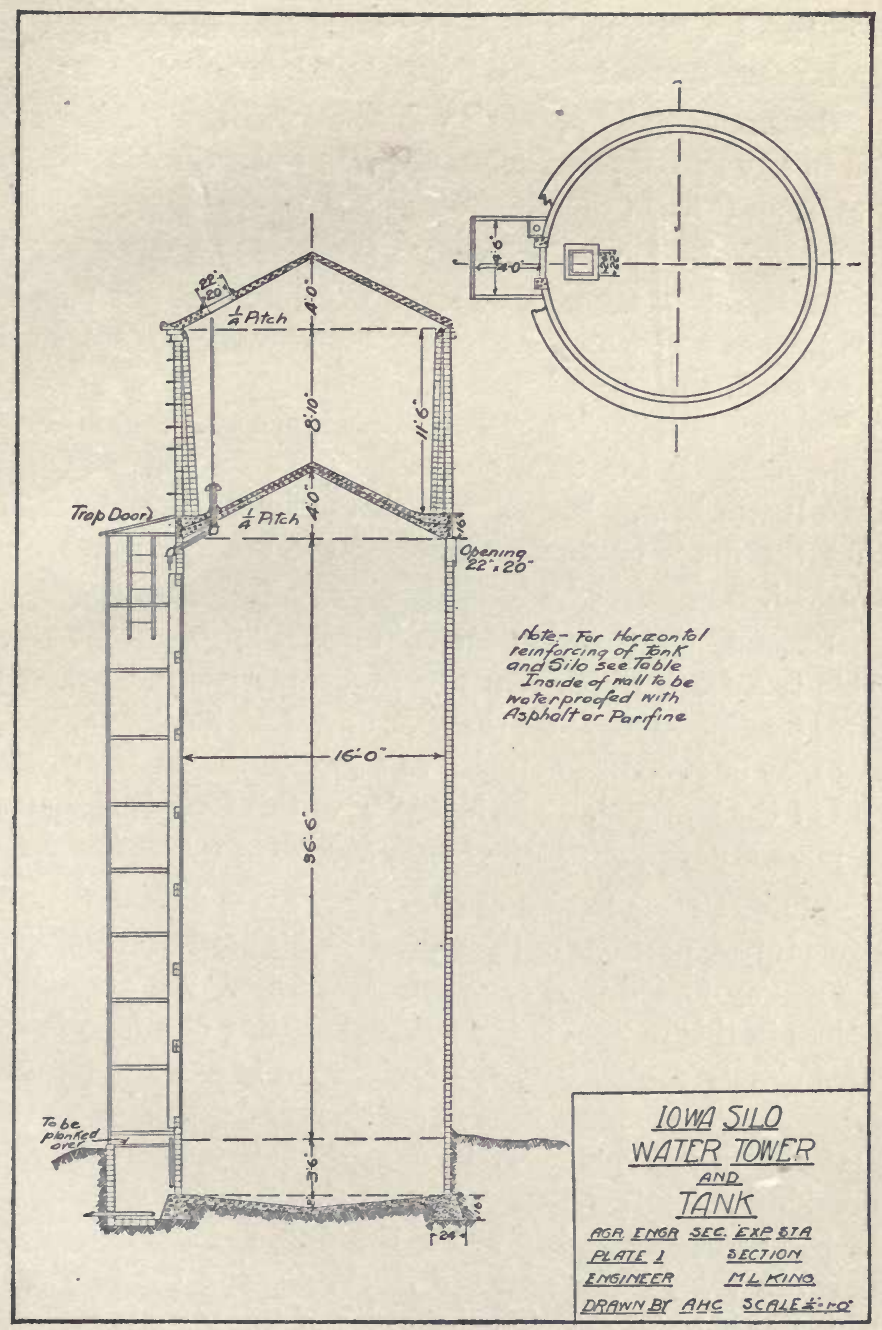

Fig. 29. Elevation of water tank. 
mentioned, where only property value is concerned, greater loads naturally are imposed than where human life is at stake.

Causes of Failure. As to their strength, materials may fail in any one of three different ways, or by combinations of two or all three of them.

First, pressure may be brought to bear which will crush the material; for instance, a block of wood may be put between the jaws of a vice and enough pressure brought to bear upon it to crush the fibers together. This is spoken of as failing in "compression." An example of this is a wall that is poorly built, or made too thin, and subjected to a greater weight than it will bear. In failing in this manner it simply means that the fibers or fine particles of the material have been crushed.

Second, the force known as "tension" may cause failure. This is a force which tends to pull materials in two. The force tending to separate the ends of a straight piece of material may be sufficient actually to separate the fibers or particles of the material. The intensity of this force is also given in pounds per square inch of cross section of the material.

Third, a force known as shear may cause failure. As the name infers, portions of the material which fail in this respect are simply forced past each other sidewise. An example of failure in this respect is the unequal settling of a foundation. This simply means that the foundation is more thoroughly supported in one place than in another, and the rigidity of the material is not sufficient to support the pressure without breaking. Another illustration of this method of failure is in case of blocks pushed out of the wall, the shear occurring between the mortar and the block, causing the mortar to slide upon the block. The intensity of this force is generally spoken of as so many pounds per square inch, and indicates 


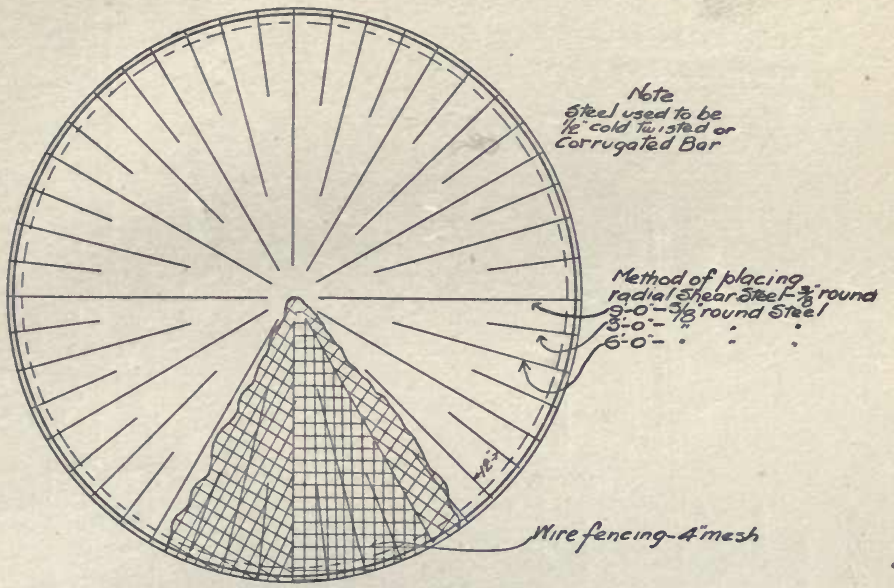

Plan View showing reinforcement of Tonk Floor scole $\%=1-0^{\circ}$
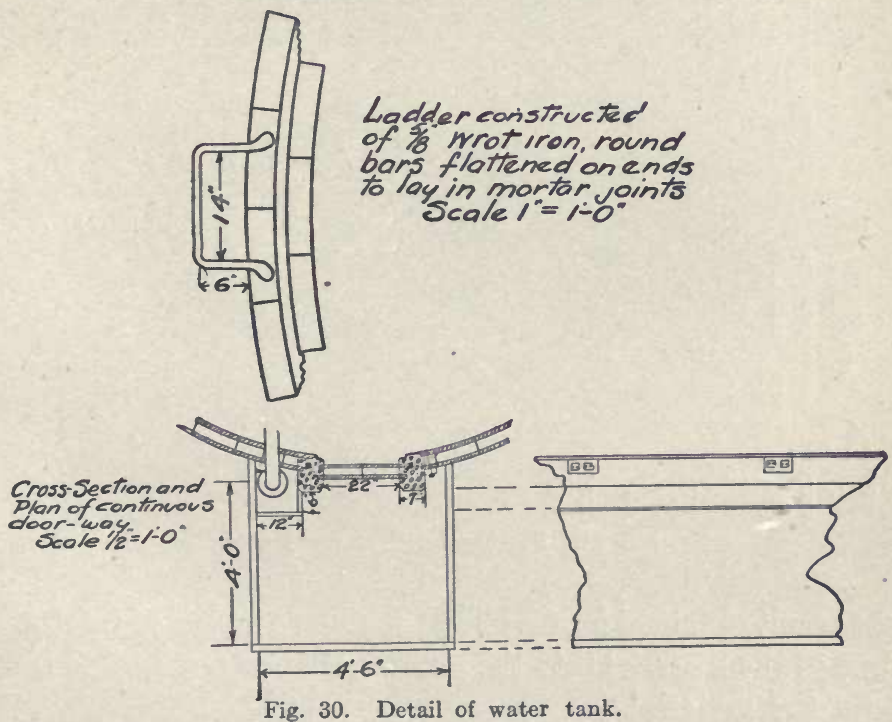


\section{Detailshowing double} connection for water pipe to be placed in metal case to avoid freezing

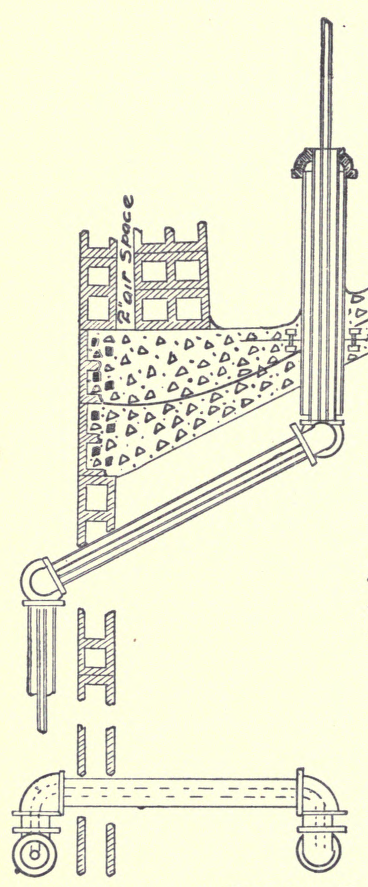

Fig. 31. Further detail of water tank.

\section{Detall showing}

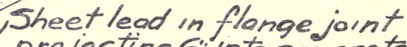
projecting 6 into concrete head gaskets to be under

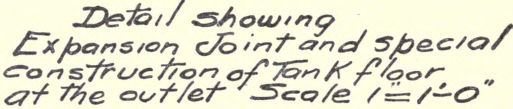

the result obtained by dividing the square inches of fractured area of the material into the pounds of force required to fracture the material. 
In bending, there is a combination of all three of these forces. As an illustration of this take a green twig, cut it off square and bend it near the cut end. It results in the crushing of the fibers on the inner part of the curve, the failure by tension of the fibers on the outer part of the curve, and often that the portion of the stick between the bend and the end is split, indicating that the endwise compression on the inner side of the curve and the tension on the outer part of the curve have been so great, pulling in opposite directions, that the material of the twig shears through the heart.

In this connection it is interesting to notice the importance of the depth of a beam. For instance, an increase in the depth of a beam increases its stiffness more rapidly than the amount of material is increased. In fact, the ability to support a load increases as the square of the proportional increase in the depth of the material. That is, a $2 \times 8$ will support 4 times as much as a $2 \times 4$, but contains only twice as much material.

Safe Strength of Materials. The following table will show the safe strength of several materials:

Table III. Safe strength of materials.

\begin{tabular}{|c|c|c|c|}
\hline Material & $\begin{array}{l}\text { Tension } \\
\text { Lbs. per sq. in. }\end{array}$ & $\begin{array}{l}\text { Compression } \\
\text { Lbs.per sq. in. }\end{array}$ & $\begin{array}{c}\text { Shear } \\
\text { Lbs. per sq. in. }\end{array}$ \\
\hline 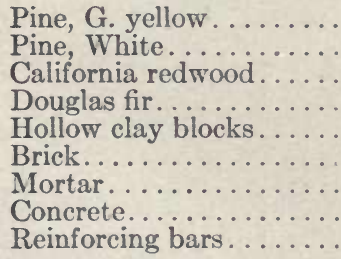 & $\begin{array}{r}2000 \\
1400 \\
800 \\
1800 \\
\cdots \cdots \\
\cdots \\
\cdots \\
15,000 \\
\end{array}$ & $\begin{array}{l}\cdots \cdots \\
\cdots \cdots \\
\cdots \cdots \\
80 \\
200 \\
250 \\
200 \\
\cdots \cdots\end{array}$ & $\begin{array}{l}\cdots \cdots \cdots \\
\cdots \cdots \cdots \\
\cdots \cdots \cdots \\
\cdots \cdots \cdots \\
60 \\
50 \\
7-10,000\end{array}$ \\
\hline
\end{tabular}

A No. 3 bright Bessemer steel wire will safely stand 1000 pounds in tension. 
In the use of any material the possibility of destruction in time, by natural agencies, such as decay or corrosion, should be considered. The probable length of life of all parts should be taken into consideration, and that which will probably give out first should be planned with the largest factor of safety. Thus in building a structure of any kind it should be built so that each part will last as nearly as possible the same length of time as every other, and when it does submit to the agencies of time it should, like the "One-Horse Shay," all fail in a day.

Splicing and Welding. The method of splicing materials should receive careful attention in order to make them as strong as other parts. Pieces of steel in concrete or mortar should hook into each other if the steel is smooth. The hooks should, of course, be thoroughly imbedded in the masonry. If twisted, corrugated, or other special reinforcing material is used, the ends should extend past each other a distance, equal to at least 18 diameters of the material. Welding should be avoided where possible, as in general it is difficult to make sure that a forge weld is perfect.

However, in cases of anchor rods, eye bolts, or similar parts, the hooks or eyes should, if possible, be welded, because the strength would then depend not only upon the stiffness of the material in the hook or eye, but also upon the strength of the weld. Hooked portions of any material should be welded unless the steel is held firmly by being imbedded in masonry.

\section{SPECIFICATIONS FOR STEEL}

Ordinary steel rods or wires do very well for silo building, and can be depended upon to withstand a pull of about 12,000 pounds per square inch. Where steel is bought especially for this purpose it is best to buy reasonably high-carbon steel or 
hard wire. It is usually safe simply to specify bright Bessemer or hard open-hearth steel wire. This will ordinarily be safe at 16,000 pounds per square inch. In other words, the No. 3 wire, which is a convenient size for silo work, will safely withstand a pull of about 1000 to 1200 pounds. For reinforcing rods to be used at the door frame, or for other general reinforcing work, corrugated or twisted bars will be found best; or, if smooth rods are used, they should be hooked at the ends so that they will not slip.

\section{CONCRETE MIXTURES}

The proper proportion for mixing material composing concrete will depend upon the kind of material used and the strength required by the service to which the concrete will be put. Concrete of the strength given in Table III is made by mixing 1 part cement with $2 \frac{1}{2}$ parts of sand and 5 parts of crushed stone, or by mixing 1 part cement with 5 parts of bank gravel which, if sifted out, would give 1 part sand to 2 parts stone.

The theory is that the particles of cement should thoroughly coat all of the particles of sand and stone, and at the same time fill in all spaces between the particles of sand and gravel which are not already occupied by smaller particles.

It will be readily seen that if only sand and cement were mixed, it would be necessary, in order to get the same strength as before, to mix 1 part of cement with $21 / 2$ parts of sand, thus giving only $1 / 2$ the quantity of concrete otherwise obtained. This indicates the importance of knowing the grade of gravel or other aggregate.

Testing the Concrete. It is easy to determine, in a practical way, the amount of cement to make a dense concrete from any quality of aggregate that is available. A represen- 
tative sample of the moist aggregate should be measured and the quantity of water determined which is required to fill to the surface of the aggregate. The proportion that this quantity of water, plus 10 per cent, is to the quantity of aggregate, is the proportion of cement to the aggregate which is required to make a dense concrete.

Tamping. From this discussion it is easy to see why concrete should be tamped, or, more properly speaking, vibrated, as any motion of the mass will cause the finer particles to settle more closely into the spaces between the larger particles. In all silo work a very dense concrete should be used. In order to remove forms promptly it is also very desirable to have a mixture rich enough to set quickly. This is especially true of the concrete used in the roof.

The presence of clay or dirt prevents the union of the cement and the particles of sand and gravel. Small quantities of dirt are usually present in bank gravel, but should not be more than 10 per cent. It is a simple matter to determine the quantity of dirt in gravel by simply washing a measured portion of the material. The wash water should be set aside to settle, and the quantity of dirt settling out should be meas- ured. The proportion of this to the quantity of gravel is determined.

Storing Cement. It seems almost needless to say that cement should be very carefully stored in a dry place. Any cement having hard lumps distributed through it should not be used. Aside from what has been given, little or no testing seems advisable on the average job.

If there is any question as to the quality of the cement, a trial sample may be mixed in the proper proportions with the gravel and allowed to stand a few days before the main 
quantity is to be used. If it sets up quickly it is, in all probability, a safe cement to use.

\section{MORTAR}

Working Quality. In the mixing of mortar it is very important to get a mortar that will be conveniently plastic under the trowel. A good mortar is usually spoken of as tough. A sand and cement mortar is not tough, but very short. In order to improve the working qualities of such a mortar it is necessary to use some lime with the cement.

Proportions. The proportion of 1 part of cement to 2 or $21 / 2$ parts of sand and $1 / 2$ part or 1 part of lime putty (slaked lime), will result in a very good mortar. A good mortar saves time and sets up rapidly enough to permit the building of a considerable height of wall each day.

\section{CLAY BLOCKS}

Vitrified Brick. Brick clay is made up of two classes of materials, one which melts at a temperature within the kiln, and the other a nonfusible substance which does not melt but holds the brick in shape. The flux or fusible material, in melting, fills the pores between the other particles of clay and melts out over the surface, giving it a glassy appearance, that is, what is known as vitrified brick. If either the shale clay or surface clay tile have these materials properly proportioned, the result of thorough burning will be very dense or vitrified brick.

The modern kiln is so arranged that the fire passes up the side of the wall and down among the brick or other material to be burned, so that the highest temperature occurs in the top of the kiln, and the most thorough burning occurs there. So even though the clay is right, only that portion located in the top portion of the kiln is right for silo construction. 
Blocks for Silos. In silo construction we have two reasons for specifying hard-burned brick; one is that it must not absorb a great amount of moisture from the silage; another is that if soft or porous brick are exposed to the weather they are not durable, as moisture freezing in the pores of the brick expands and causes the block to disintegrate. This has been noticed by every one in the case of soft drain tile which have been allowed to lie in a slough over winter.

In order to make sure that brick or clay blocks are right for silos it is necessary to buy only such brick or blocks as will absorb an average of 5 per cent or less of their weight of moisture. No block should be used that absorbs over 8 per cent. If this quality is secured the result will be a good durable silo, if it is put together with other good material by a good workman.

In addition to this, it should be specified that all blocks fit the circle within $1 / 8$ of an inch. When ordering blocks it should be borne in mind that uniform color of blocks is quite desirable and greatly increases the appearance of the building.

Absorption Test. A convenient method of determining the amount of water these products will absorb is either to take the blocks hot from the kiln or place them in an oven where they will have a temperature higher than boiling water continually for two days. Then they should be weighed and placed in water for a couple of hours or until they cease to increase in weight. The increase in weight divided by the dry weight gives the percentage of the absorption.

This same test will indicate whether or not there are lime nodules in the clay. Sometimes pebbles of limestone occur in the clay, which, when the clay is burned, become quicklime, and this exerts a swelling force when it comes in contact with water. This force is such as to chip off or split the material. 
If the concrete absorbs more than 10 per cent of its weight of water it should be plastered or coated with asphalt in order that it will not draw too much moisture from the silage. 


\section{CHAPTER X}

\section{BUYING AND CONTRACTING OF SILOS}

When to Plan. The man who gets what he wants is the man who looks the farthest ahead. Ordinarily a man can as well decide in January as in August. or September whether or not he can profitably use a silo, and he should do so. It is important, in buying or arranging for the building of any kind of silo, that plenty of time be allowed for its delivery and other fulfilment of the contract. This is a matter of importance to everyone concerned, in securing a better grade of material and workmanship. It gives the farmer time in which to return any inferior material in case such is delivered. Even though a certain grade of material is specified, it is difficult to secure a second shipment in exchange for inferior material when it is not delivered until late in the season.

In buying wood, the kind and grade of wood should be specified. The choice of the grades of lumber will usually depend upon the amount of money which can be invested. It is also important, with most kinds of wood, to specify that little or no sapwood shall be found in the lumber; that is, it should be very largely heartwood. It should always be agreed in writing that any lumber not coming up to the specifications shall be replaced, with no cost to the purchaser, and that delivery shall be made early enough in the season to give opportunity for this replacement. 


\section{CONTRACT}

THIS AGREEMENT made and entered into this..... day of. . $.191 . .$, by and between.

County of .............., State of hereinafter called the "owner," and

Town of of . .......... called the "contractor."

WITNESSETH: That in consideration of the sum of dollars to be paid the contractor by the owner as soon as work hereinafter contracted for has been completed, said contractor hereby agrees to erect and construct, or cause to be erected and constructed for the above named owner on his premises, to-wit, on ............. in County, State of.

a silo of the type known as .............. Said silo to be................ in size and constructed as follows, to-wit:

The foundation shall extend below frost ..... feet and shall be at least 16 inches wide at the bottom. The top of said foundation shall be at least one foot above the surface of the ground, foundation to be made of concrete, mixed by taking five parts sand and gravel and one part cement, said foundation to be sixteen inches wide at the bottom and ....... high, and to be.............. wide at the top. On top of said foundation a .............. wall shall be constructed of ............. to be used from the footing 
to the top of silo. The silo wall is to be securely and properly reinforced with steel. On one side of said silo a door 22 inches wide in the clear is to be constructed, commencing near the bottom of said silo and extending to within about five feet of the top of the silo. On each side of said door opening from the bottom of the first opening and extending to the top of the last opening, door-jambs are to be built of concrete, made by mixing four parts sand and gravel and one part cement. In said door space are to be placed horizontally reinforced concrete crossties about every four feet. The silo is to be covered with concrete roof conical in shape, properly reinforced, and an opening of convenient size is to be left, therein for the filling of the silo. 


\section{IN D E X}

Absorption test, 94.

Acidity in silage, 11.

Air spaces in wall, 20.

Bacteria in silage, 11.

Blocks, construction, 94 .

Block silo, 35, 65.

Brick silos, 37, 93.

Buying and contracting of silos, 96.

Capacity of round silos, 43 .

Cattle, amount of silage to feed, 44.

Cement block silos, 35 .

Cement, storing, 92; tamping, 92; testing, 91; wash, 65.

Chute, 50.

Clay blocks, 93.

Clay products silos, 35,65 .

Compression, 86.

Concrete mixtures. 91.

Concrete silos, 32, 34; monolithic, 60 .

Continuous doors, $8,25,28,76,82$.

Contract for silos, 96.

Corn for silage, time to cut, 11 .

Cost of silos, 41 .

Cresote for wood silos, 24 .

Crosstie of block silos, 68, 77.

Derrick, 75 .

Doors, details of, 48 ; hinge, 30 ; improvement, 8; independent, 27; Indiana, 29; wooden, 82.

Door forms, construction, 78, 80 .

Door frames, construction, 74; improvement, 8.

Drainage of silos, 47.
Early development, 7 .

Ensilage, poisoning from, 13; preservation of, 11 .

Excavating, 46.

Factor of safety, 84 .

Failure, causes of, 86 .

Feeding silage, amount, 44.

Fermentation of silage, 11 .

Fire exposure, 17.

Floors, 51.

Forage or mold poisoning, 13; causes, 13; prevention, 16; symptoms, 15.

Forms, 60 .

Foundations, 46.

Frame silos, 24.

Frozen silage, 18.

Guide for wall, 71.

Gurler silo, 25.

Guying the silo, 28.

Heat, how lost in silo, 18.

Hinge door, 30 .

Hoisting, methods, 64, 74, 75.

Independent door, 27.

Indiana door, 29.

Influence of material on silage, 21 .

Interlocking block silos, 38 .

Iowa silos, 65; building, 71; perspective view, 81 ; scaffolding, 67.

Location for silo, 39 . 

Masonry silos, advantages, 31 ;
development, 10; kinds, 32 .

Material for silos, influence of, 21 ; safe strength of, 84 .

Mold, cause of in silage, 12 .

Mold poisoning, 13.

Monolithic concrete silos, 60 .

Motar, 93.

Painting wood silos, 23.

Planning the silos, 39, 96.

Pit, 7, 46.

Plastered silos, 34 .

Plastering concrete silos, 64 .

Poisoning from silage, 13.

Preservation of silage, 11; air spaces in walls, 20; frozen silage, 18; influence of materials, 21 ; nature of process, 11 ; moldy silage, 13; settling, 17 .

Reinforcement, 60, 63; of door frames, 74 .

Reinforcement table, 78.

Roof construction, 79 .

Roof plans, 49, 79 .

Round silo, development, 8.

Safe strength of materials, 84 .

Scaffolding, for block silo, 67; stave silos, 52.

Settling of silage, 17.
Sheathing, 50 .

Sheep, amount of silage for, 44 .

Silage preservation, 11.

Shear stress, 86.

Size of silo, 43.

Splicing, 90.

Square silo, 8.

Stave silo, 21, 27; erection, 52 .

Steel, 63, 90.

Stone silos, 32, 33 .

Tamping concrete, 92 .

Tension, 86.

Testing concrete, 91 .

Unandilla door, 28.

Vitrified brick, 93 .

Wall, air spaces in, 20 ; constructing, for Iowa silos, 65 ; materials of, 17,21 ; quality of silage at, 11.

Water tank on silo, $85,87,88$.

Welding, 90.

Wisconsin silo, 8, 24.

Wood for silos, 23, 96 .

Wood hoop silo, 25.

Wood silos, 23. 


\section{STANDARD BOOKS FOR FARMS AND FARM SCHOOLS}

We can supply any book published on General Farming, Gardening, Dairy, Live Stock, Horticulture, Forestry, Soils, Poultry, Bees, etc. All inquiries and orders for Farm Books will receive prompt attention.

Beginnings in ANIMAL HUSBANDAV cspowa

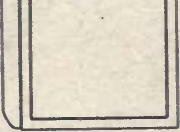

\section{Beginnings in Animal Husbandry}

By Prof. C. S. Plumb, of the Ohio State University College of Agriculture. Author of "Types and Breeds," etc. It teaches in a very interesting way what every farmer and farm boy ought to know about types and breeds, judging, breeding, feeding and care of farm animals and poultry. No book like it has ever been published. 393 pages; 216 illustrations. Cloth bound, $\$ 1.25$; postage 12c extra.

Field Crops A new standard book by A. Agr., and C. W. Warburton, U.S. Dept. of Agr., on the best methods of growing, harvesting and marketing farm crops; seed selection; fertilizers; cost of production; rotations; and weeds. Handsomely bound; 544 pages; 160 illustrations. A practical book by practical men. Cloth bound, $\$ 1.50$; postage $17 c$ extra.

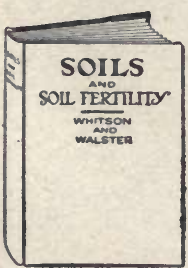

\section{Soils and Soil Fertility A clear,} nical discussion, by Profs. A. R. Whitson and H. L. Walster, of the Wis. College of Agr., presenting the foundation principles of soil management. It tells clearly how to make simple tests of soils to discover their needs; how to fertilize, till, and otherwise handle different types of soil, as sandy, marsh and clay soil. It will answer your perplexing soil questions. 315 pages; well illustrated; nicely bound. Cloth, $\$ 1.25$; postage $12 \mathrm{c}$ extra.

Make all Remittances by Postoffice or Express Orders, or New York, Chicago, or St. Paul Drafts.

\section{Webb Publishing Co., St. Paul, Minn.}




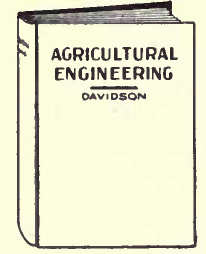

Agricultural Engineering $\underset{\mathrm{Da}}{\mathrm{By}} \mathrm{J}$. B son, Iowa State College of Agriculture. A complete and practical handy manual text book of all engineering problems of the farm, including land surveying, drainage, irrigation roads, farm machinery and farm motors, farm buildings, and sanitation. It will be the most effective aid in farm management; 544 pages; over 300 illustrations; a handsome book. Cloth $\$ 1.50$; postage $15 \mathrm{c}$ extra.

\section{Popular Fruit Growing By the late}

Green, Minn. College of Agri. A very popular treatise on horticultural methods and practices. Gives principles of successful orchard management and small fruit culture, fruits adapted to each state, how to ward off insects and diseases, harvesting and marketing methods. A standard text in many schools. 300 pages; profusely illustrated. Cloth, $\$ 1.00$; postage 12c extra.

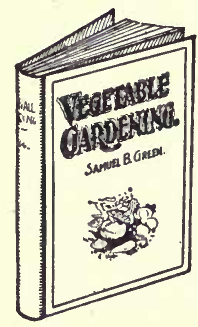

Vegetable Gardening By S. B. Green, Horticulture, Minn. College of Agri. A handy manual on the growing of all kinds of vegetables for home use and for the market. It is used as a practical school text book and is indispensable to farmers and gardeners everywhere. 122 illustrations; 252 pages. Twelfth edition. Cloth $\$ 1.00$. Paper cover, 50 cts. Postpaid.

\section{Agriculture for Young Folks} By A. D. Wilson, Supt. of Farmers' Institutes and Agricultural Extension, University of Minn., and E.A. Wilson. This is the most practical elementary agricultural text book for rural and graded schools ever published. It presents the elementary principles of agriculture through lessons based on practical farm problems. 340 pages; well illustrated; cloth bound. Price $\$ 1.00$. By mail 10 cents extra.

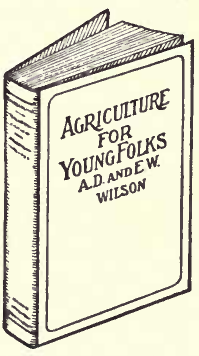

\section{Webb Publishing Co., $\quad$ St. Paul, Minn.}




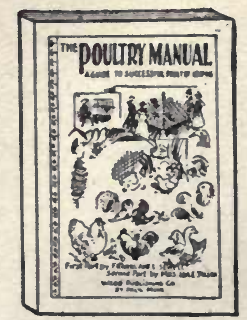

Poultry Manual A standard guide try keeping, by F. L. Sewell and Ida E. Tilson, both well known authorities on domestic fowls and their keeping. Selection and breeding for egg production, rations and methods of feeding and general care of fowls are emphasized. Well illustrated; 148 pages. Cloth, 50 cents. Paper covers, 25 cents.

\section{The Country Kitchen $\begin{gathered}\text { A book of } \\ \text { household }\end{gathered}$} recipes, all contributed by farmers' wives and daughters, readers of The Farmer. This is a choice collection of over 900 of the best recipes which have been recelved. It has been printed in many editions, and is today the most popular book of its class published. It is sure to prove a most helpful servant in your kitchen. Cloth bound, 50 cents. Paper covers, 25 cts. Postpaid.
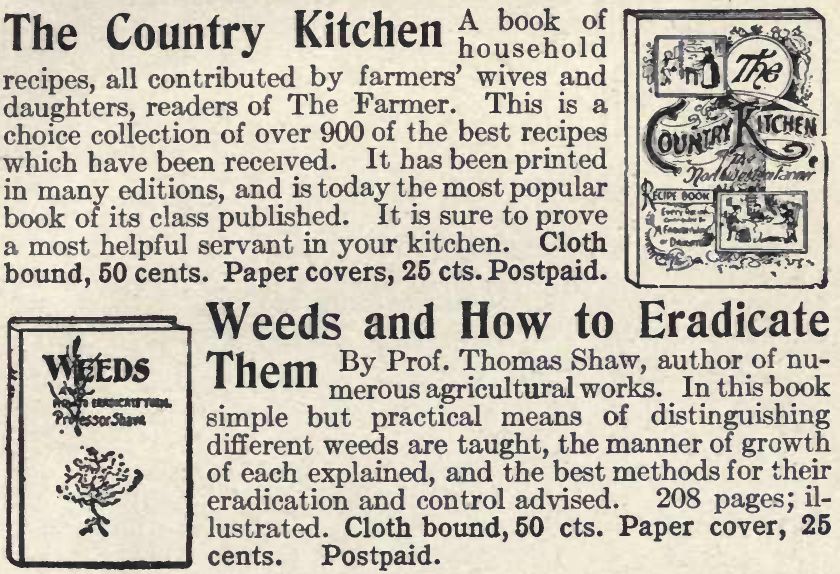

\section{Quack Grass Eradication ${ }_{\text {Crane, }}^{\text {By P. B. }}$}

practical farmer who has worked out a system of soil treatment which results in a permanent destruction of quack grass. It is not necessary to lose a crop by this method, nor are expensive tools needed. The principles involved are plainly stated and the process itself in not complex. This book should be in the hands of every farmer on whose farm quack grass is spreading. Cloth bound, $\$ 1.00$. Postpaid.

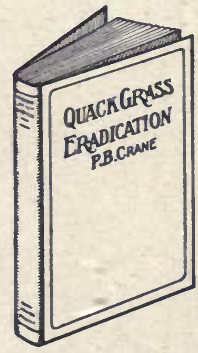

\section{Webb Publishing Co., St. Paul, Minn.}




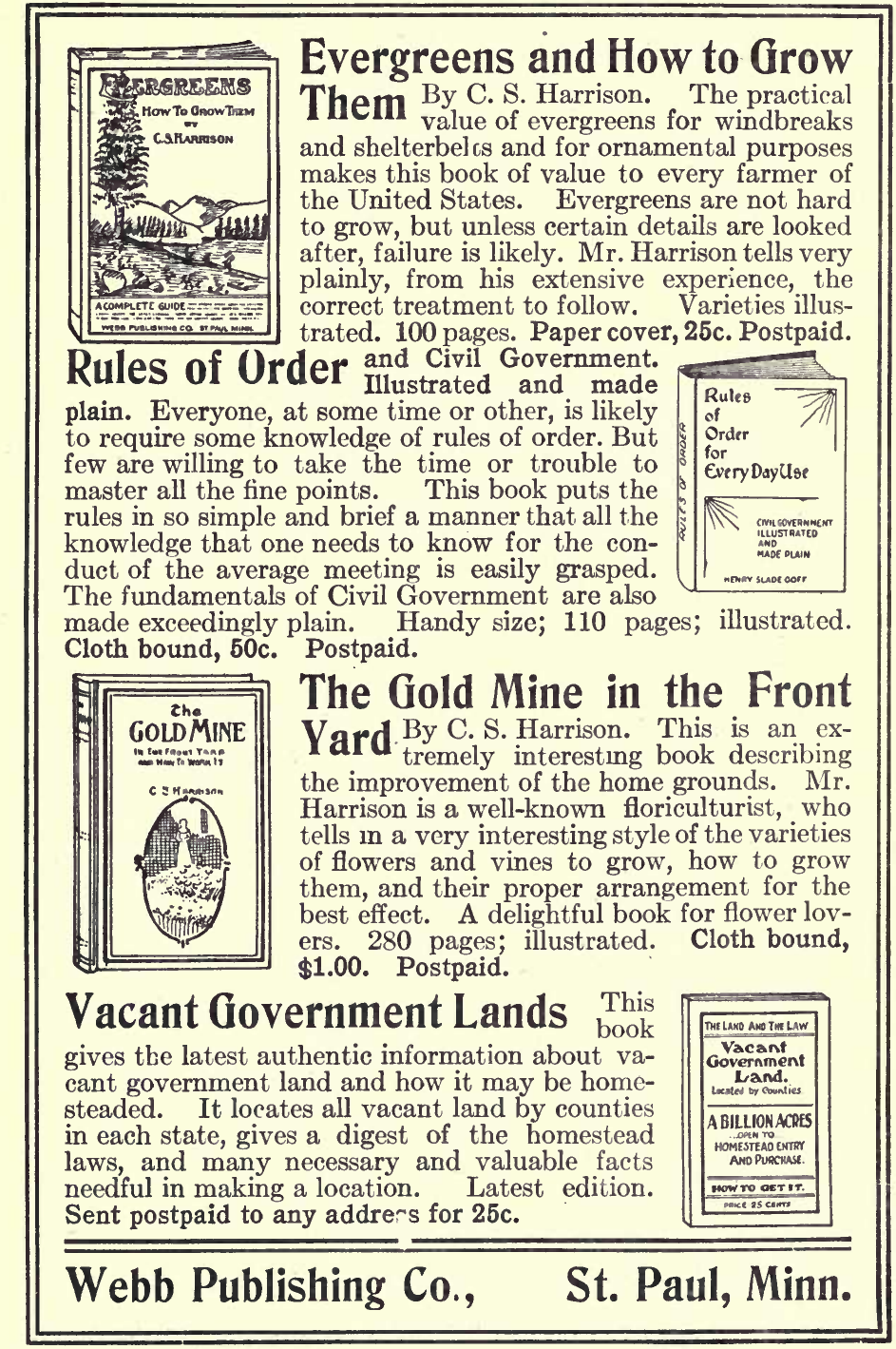




$\omega=5 h$

$50 \mathrm{men}$

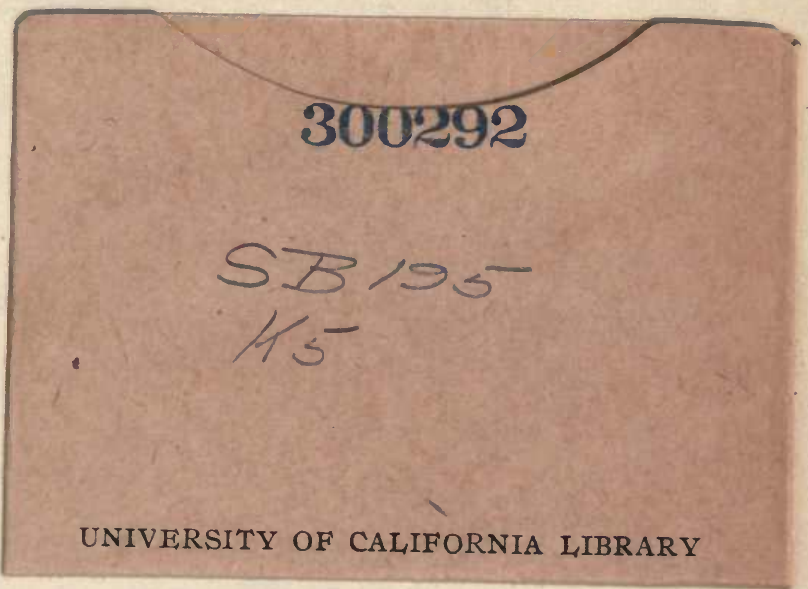

UNIVERSITY OF CALIFORNIA LIBRARY 


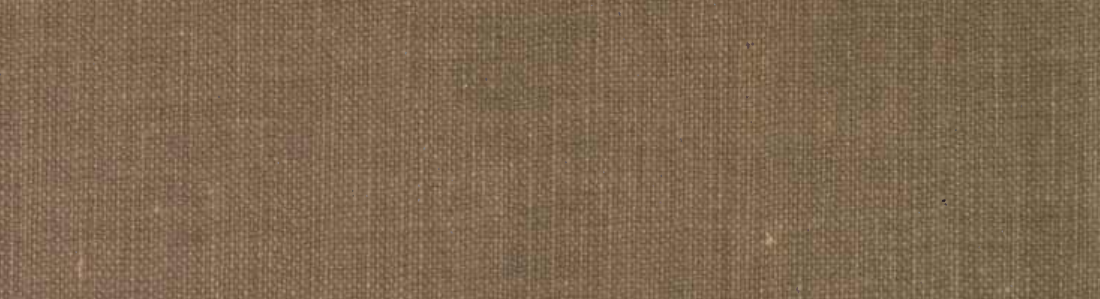

:

(2)

3.

35

(3)

-

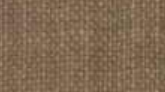

(5)

(1)

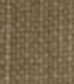

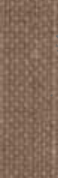

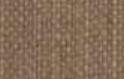

